Voix et Images

voixetimages

\title{
Entrevue avec Michel van Schendel
}

\section{Jacques Allard et Chantal de Grandpré}

Volume 11, numéro 2 (32), hiver 1986

Michel van Schendel

URI : https://id.erudit.org/iderudit/200553ar

DOI : https://doi.org/10.7202/200553ar

Aller au sommaire du numéro

Éditeur(s)

Université du Québec à Montréal

ISSN

0318-9201 (imprimé)

1705-933X (numérique)

Découvrir la revue

Citer ce document

Allard, J. \& de Grandpré, C. (1986). Entrevue avec Michel van Schendel. Voix et Images, 11(2), 167-219. https://doi.org/10.7202/200553ar d'utilisation que vous pouvez consulter en ligne.

https://apropos.erudit.org/fr/usagers/politique-dutilisation/ 


\title{
Entrevue avec Michel van Schendel
}

\author{
par Jacques Allard et Chantal de Grandpré, \\ Université du Québec à Montréal
}

\section{Naître}

V. \& I.(1)' - La question des origines est importante pour beaucoup ici au Québec; il y a des gens qui te croient juif, ou qui te croient belge alors que tu es né en France de parents belges. Quelle est l'importance pour toi de cette question des origines?

M. v. Schendel ${ }^{2}-C^{\prime}$ 'est une question immense qui en même temps est très étroite.

V. \& I.(1) - Tu es content de ton origine flamande, en fait. Tu la chantes et tu la privilégies quand tu le veux, quand tu le peux.

M. v. Schendel - Je ne sais pas si elle est flamande d'ailleurs, je dirais qu'elle est cosmopolite. Mon grand-père était fils de hollandais. Mon père a immigré en France; il a vécu dans le pays flamand mais il a immigré en France après la guerre qu'il avait faite dans l'armée belge. Il a passé tout le reste de sa vie en France. Et c'est là que je suis né et c'est là que je suis revenu après la Deuxième Guerre mondiale. C'est pas une origine flamande. Si c'est une origine flamande, c'est aussi d'autres origines et il y a un rapport très étroit au fait que je suis devenu français et que j'ai choisi de l'être. Et pour moi c'était d'ailleurs très important au plan anecdotique, très important cette conquête à l'époque, parce que j'avais la Belgique en horreur. Je l'avais en horreur, du moins était-ce peut-être le milieu social dans lequel je vivais, un milieu... disons la grande bourgeoisie du XIX ${ }^{\text {e }}$ siècle, ruinée, conservant une morale très étroite, et une moralité aussi très étroite... un horizon social physiquement très fermé. Quand j'étais petit, l'interdiction de jouer avec les enfants du peuple... Mais à travers tout ça, et surtout pendant la guerre, l'expérience d'une très grande misère, une très grande misère physique et sociale. Cette contradiction, elle, a beaucoup compté, cette contradiction de l'horizon social en amont, je crois qu'elle a fait ce que je suis devenu après la guerre. Mais il fallait d'abord, dans un premier temps, que je quitte la Belgique. Si j'étais resté là, peut-être que je n'aurais pas eu le courage de quitter aussi radicalement ce milieu social. Si j'en juge par ceux de mes frères qui sont restés, eux n'ont pas du tout coupé les ponts, bien au contraire, ils les ont raffermis. 
V. \& I.(1) - Dans ce milieu social, quelle place fais-tu à tes parents et ton rapport à ton père et à ta mère? Est-ce que ta réaction très vive était celle de qui a vingt ans...?

M. v. Schendel - C'était même avant l'âge de vingt ans. C'était une réaction de l'adolescence et une réaction à la guerre aussi. Mais, bien sûr, ça passe également par des liens familiaux puisque l'horizon social étroit tendait à être borné par la famille ou par un appareil qui dépend très étroitement dans de telles conditions de l'appareil familial, c'est-à-dire l'appareil scolaire, le collège des jésuites. Heureusement d'ailleurs - je suis athée de gauche - je ne regrette pas d'avoir passé dix ans chez les jésuites. Ils m'ont appris à penser. Ils ont été une première forme de libération pour moi.

V. \& I. (2) ${ }^{3}-$ Je trouve cela intéressant dans la mesure où le Québec a été aussi beaucoup dominé par les jésuites. Est-ce que vous n'avez pas retrouvé ici des choses qui vous étaient familières d'une certaine manière?

- M. v. Schendel - C'est possible, oui. Je ne me suis jamais trop posé la question. Oui, mais en même temps non, parce que... Je ne sais pas. Évidemment, la question n'est même pas hypothétique, étant donné que je ne suis pas né ici, je n'ai pas grandi ici, je ne sais pas si né ici, ayant vécu toute ma vie ici je serais, $j$ 'aurais trouvé le même horizon social en amont et je ne sais pas... Enfin je suis un Européen, ça compte. À l'origine je ne suis pas un Québécois et je suis marqué par une expérience qui est l'expérience de notre siècle. Parfois, je me sens un petit peu à l'étroit ici parce que je ne sens pas suffisamment cette imprégnation de l'expérience du siècle ici, de notre siècle. L'expérience de notre siècle, elle est en ébullition tragique pendant la guerre. La guerre résume le siècle, la Deuxième Guerre mondiale, et elle continue de le résumer après. On ne peut pas comprendre ce qui se passe aujourd'hui si on ne pense pas à ça. Il y a aussi autre chose. Il y a des jésuites, d'accord!, pour essayer de répondre à votre question mais il y a l'après-guerre et l'aprèsguerre fut une expérience de libération personnelle qui bientôt tend à rejoindre une expérience qui m'apparaissait telle à l'époque, d'une libération politique et sociale. Donc une orientation prise du côté du parti communiste. Pourquoi? parce que c'était à l'époque la seule force organisée qui permettait de relancer cette lutte dont $\mathrm{j}$ 'avais besoin personnellement. Et mon expérience individuelle me semblait coïncider, surtout, de plus en plus, me parut coïncider, avec l'expérience collective de l'époque. Ce que j'avais vécu dans ma jeune vie recoupait, ce n'est pas métaphorique ou alors c'est la métaphore blanche, c'est une métaphore qui est le mouvement même de cette vie, cette expérience bouleversée d'époque, que j'apprenais à découvrir en même temps dans ce qu'elle avait de plus bouleversé pour les pays d'Europe occidentale, c'était la classe ouvrière.

V. \& I.(1) - Mais comment as-tu vécu la guerre, tu as dix ans quand elle se déclenche en 39 et jusqu'à 46 tu restes à Bruxelles. Comment l'as-tu vécue?

M. v. Schendel - J'ai vécu toute la guerre à Bruxelles, très mal, très misérablement. 
V. \& I.(1) - J'aimerais que tu le rappelles sommairement. Où es-tu? Tu es au collège des jésuites, tu es pensionnaire loin de tes parents?

M. v. Schendel - Non. Nous sommes à l'époque très pauvres. Et comme les jésuites reconnaissent «les vertus sociales de la bonne éducation", ils avaient accepté de prendre les quatre fils gratuitement. Heureusement, en un sens. Mais dans un autre sens c'était, malgré leur intention, une source d'humiliation à cause des contacts avec les fils de familles riches. Pendant la guerre, alors là, c'est très très physique, j'ai écrit tout un texte là-dessus, c'est donc une sorte de roman autobiographique. J'en ai publié la première partie dans Voix et images du pays en 71 . C'est une expérience très physique. Immédiatement physique: c'est la faim et le froid. Nous n'avions pratiquement pas de quoi manger et n'avions pas non plus de quoi nous chauffer. Les hivers, en particulier l'hiver 41 et l'hiver 43 , avaient été extrêmement durs. Des hivers en Europe où la température descend à moins 20 ce n'est pas fréquent. Et il n'y avait pas de charbon. Il y avait les tickets de rationnement pour se procurer un peu de charbon et se procurer un peu de nourriture. Mais ma mère qui était séparée de mon père était beaucoup trop pauvre pour pouvoir émarger au marché noir comme le faisaient - et c'est là que nous connaissions les expériences d'humiliation - les fils des familles riches que nous fréquentions au collège et j'étais très religieux à l'époque, très croyant. J'ai radicalement remis ça en question, après la guerre d'ailleurs. Il y a des coïncidences qui sont beaucoup plus que des coïncidences. J'étais très croyant, je servais tous les matins à la messe, à huit heures du matin et après la messe, après la communion, je déballais quelques petites tartines très minces de pain qui n'était pas du pain, qui était fait on ne savait pas avec quoi, un minimum de farine qui ne parvenait pas à tenir et sur lequel il y avait très peu de margarine. Je déballais ça et mes collègues, eux, arrivaient avec de grandes tartines, de grosses tartines de pain blanc. Pendant la guerre c'était proprement scandaleux, scandaleux pour tous ceux qui n'avaient pas de quoi manger. Et il y avait des couches épaisses de beurre... Ca, c'est une expérience humiliante surtout qu'elle était relevée sous mon nez, avec insistance. J'ai eu ça en horreur. Ma mère m'a obligé à y rester quand même trois ans. Une fois il y avait un camp scout et chacun devait apporter de quoi alimenter la nourriture collective et alors ma mère avait fait ce qu'elle pouvait mais c'était pas grand'chose, j'apportais donc beaucoup moins que les autres. Le chef scout m'avait fait venir et m'avait dit: tu n'as pas honte?... Tu comprends, tu ne le souhaites pas. Alors le froid, la faim. Et la maladie: j'ai été assez gravement malade pendant la guerre surtout que j'étais en pleine croissance. J'ai eu une pleurésie. À l'époque il n'y avait pratiquement pas de médicaments, on n'avait pas découvert la pénicilline; on l'avait découverte mais enfin elle n'était pas commercialisée dans les pays occupés par les nazis. Et puis il y avait aussi l'expérience... ce n'était pas la soupe populaire, c'était la soupe populaire organisée par les nazis où servaient les dames patronnesses qui étaient les anciennes camarades, et là ça se redoublait aussi, les anciennes camarades de classe, dans tous les sens du terme, de ma mère et qui étaient parfois aussi les mères de certains de mes camarades de classe. Ce genre de choses, ça marque évidemment beaucoup et moi ce que ça m'a appris... et je 
m'étonne que l'expérience n'ait pas été la même pour mes autres frères qui cependant ont connu la même chose, auraient pu en tirer la même leçon. Eux, ça les a conduit à se ranger. Moi ça m'a conduit ... pendant la guerre, je me rappelle très bien, c'était comme si je voyais le monde se déchirer physiquement. Se déchirer par ce qu'on apprenait par les nouvelles, par des rafles dans la rue. Se déchirer donc de cette violence mais aussi se déchirer d'une violence sociale considérablement aggravée parce que plus nue, plus physiquement marquée qu'avant la guerre. C'était une contradiction vivante dont j'ai essayé par la suite, du moins c'est comme ça aujourd 'hui que je le vois (et depuis longtemps), de réfléchir le dynamisme.

V. \& I.(1) - Pour toute cette époque de la formation et de la guerre, est-ce que déjà il y avait chez toi un goût et une propension à l'écriture?

\section{M. v. Schendel - Oui.}

V. \& I. (1) - De quelle manière? Est-ce que tu as eu des professeurs qui t'incitaient à écrire?

M. v. Schendel - - C'est d'abord arrivé en 43 ou 44, j'avais 14 ou 15 ans. Je suivais un cours facultatif de musique, d'histoire de la musique. Le professeur, c'était un musicien, - un très bon pianiste, il jouait du Fauré - mais qui n'avait qu'un piano désaccordé, enfin il faisait ce qu'il pouvait. Il nous apprenait le solfège et il nous apprenait aussi des rudiments d'histoire de la musique et, il se mettait au piano parfois pour souligner son enseignement. Donc, ce n'était pas vraiment du jeu, c'était le jeu exemplaire, si je peux dire, c'était l'exemplarisation plutôt. Et une fois il avait joué le "choral et fugue" de Bach et ça m'avait complètement bouleversé, mais vraiment. Il est vrai que déjà à cette époque, dans ma famille du côté de mes grands-parents et de ma tante qui était pianiste elle-même, il y avait un accent comme dans toute bonne vieille famille bourgeoise, et plus aristocratique que bourgeoise, un accent mis sur la musique. Donc, j'y étais préparé à ce bouleversement. Et ce bouleversement... j'étais alors rentré complètement fou à la maison et je m'étais mis à écrire un texte... faudrait voir, pas ici en tout cas... après la mort de mon père j'ai retrouvé certaines de mes affaires quand j'étais enfant et adolescent... j'ai retrouvé ce texte... bof c'était plus qu'ingénu, c'était peut-être un peu stupide, mais peu importe, c'est là vraiment que m'est venu le goût d'écrire et plus tard aussi mais ça c'est juste à la fin de la guerre, en 44-45. J'ai eu la chance d'avoir un professeur qui m'aimait beaucoup, un jésuite, passionné de la Révolution française, on trouve de tout chez les jésuites, et qui m'a donné le goût de l'histoire. J'étais passionné d'histoire, je lisais énormément. Tout ce que je lisais, c'était de l'histoire. Et aussi qui m'a fait découvrir la poésie. Il m'a poussé dans ce sens-là et à la fin de l'année j'avais fait $d$ 'ailleurs une conférence sur les romantiques anglais.

V. \& I.(1) - Donc, tu lisais les romantiques anglais à 14 ans.

M. v. Schendel - En traduction. 
V. \& I.(1) - Est-ce qu'il y avait d'autres écrivains importants pour toi dans ton adolescence?

M. v. Schendel - Oui. Des romantiques anglais, il y avait surtout Shelley et Keats. Assez peu Byron... C'est une préférence que j'ai continuée d'ailleurs. Mais aussi les romantiques et les symbolistes français. Baudelaire. Rimbaud très peu. Rimbaud, on avait tendance à le mettre à l'écart.

V. \& I.(2) - On ne vous a pas fait lire Hopkins?

M. v. Schendel - Non. Pas du tout. À partir de ce moment-là, je me suis mis - ça c'est l'après-guerre qui commence - je me suis mis à écrire régulièrement mais je n'ai rien publié...

V. \& I.(1) - Un journal?

M. v. Schendel - Non, des poèmes. Beaucoup, beaucoup, des quantités de poèmes. J'ai jamais rien publié sauf plus tard quand j'étais membre du Parti j'ai publié quelques petits poèmes.

V. \& I.(1) - Et tes poèmes de cette époque-là étaient très personnels ou déjà étaient des poèmes comme tu dis de circonstances ou d'observation, d'aeil et d'écoute.

M. v. Schendel - Je dirais que c'était personnel, oui, plutôt intimiste d'une parrt. Et d'autre part, mais ça c'est surtout à partir de l'inscription sociale dans le parti communiste, je me suis mis à écrire des poèmes politiques.

\section{Prendre parti}

V. \& I.(1) - Venons-en à cette époque parisienne. Comment ça se passe? Tu arrives à Paris, tu vas t'inscrire au parti communiste?

M. v. Schendel - Non, non pas du tout... Il y avait un certain nombre de choses à régler, un contentieux à régler. La première année que j'ai passée à Paris fut très pénible. J'étais complètement désorienté, perdu. J'étais en science po. et, moi, je venais, pauvre petit Belge, d'un collège où finalement $\mathrm{j}$ 'avais appris très peu de choses. Je venais pour faire mes études universitaires et en même temps j'étais complètement déphasé par rapport à ces autres étudiants du même âge que moi qui étaient brillantş, qui paraissaient très articulés, qui avaient un savoir étendu, toutes choses que je n’avais pas. Mon expression était pénible, même si j'avais lu beaucoup dans mon enfance et mon adolescence, c'était un savoir qui n'était pas unifié, qui n'était pas articulé sur une connaissance relativement étendue de la littérature moderne. $\mathrm{Ce}$ que je connaissais de la littérature c'est, à part ce que je vous ai dit, des romanciers comme Duhamel et Mauriac. Un peu Gide grâce à ma grand-mère qui me fit découvrir Gide. Mais j'étais culturellement, au plan de la culture seconde, j'étais un arriéré.

V. \& I.(1) - Mais tu n'as que 16 ans! 
M. v. Schendel - Non, en 46, j'ai 17 ans. Oui bien sûr, mais peu importe : à 17 ans on est un petit homme. Et d'autre part je constatais que ces autres étudiants, du moins, à l'Institut d'études politiques, étaient beaucoup plus formés que moi. Ils avaient le même âge. Et aussi, c'était une période assez difficile parce que précisément j'avais à régler un contentieux sur l'université. Ce contentieux c'était évidemment l'amont familial mais c'était aussi la religion. Il a fallu d'abord que je règle ça.

\section{V. \& I.(1) - Comment ça c'est passé?}

M. v. Schendel - Ca c'est passé péniblement mais radicalement. C'est-à-dire qu'un jour j'ai découvert que ça n'existait pas. Que oui, la religion avait une force sociale considérable, qu'elle reposait sur des articles de foi absolument impénétrables et qui n'avaient pas besoin d'être démontrés et que par conséquent c'était à eux, si ça les amusait, d'essayer de me le démontrer, mais moi ça ne me concernait plus. Par conséquent, ça s'est arrêté là.

V. \& I.(1) - Est-ce qu'on peut aussi dire que c'est une conscience politique plus nette qui te vient à 17 ans, quand tu arrives à Paris, à l'Institut des sciences politiques. C'est là que tu t'inscris en arrivant?

M. v. Schendel - C'est là que je m'inscris et à la faculté de droit aussi. Aux deux à la fois. Et j'ai raté tout. J'ai tout raté. Pour les raisons que j'essaie d'exposer. Parce que... il y avait... c'est comme me sortir d'une gangue. J'étais au fond un petit bébé, ou une petite chenille quoi. J'avais à sortir de la chrysalide. La chrysalide c'était aussi, et je reviens à la question que tu posais tout à l'heure, c'était la mère qui avait été extrêmement présente, d'autant plus présente qu'elle n'avait pas de mari et qu'elle en avait absolument besoin et qu'elle ne voulait aller avec aucun homme, ce qui était totalement absurde.

V. \& I.(1) - Mais tu voyais ton père de temps en temps?

M. v. Schendel - Ah oui! Mon père, et c'était une des raisons pour lesquelles je suis venu en France, habitait la France, ma mère la Belgique. C'était aussi un choix. Je me sentais bien avec mon père.

V. \& I. (1) - Mais qu'est-ce que faisait ton père à cette époque-là à Paris? Est-ce qu'il était déjà marchand de biens?

M. v. Schendel - Oui. Dès la fin de la guerre il avait relancé ses affaires: commerce et promotion immobilière à Paris et c'est lui qui m'avait fait venir mais je ne vivais pas avec lui, je vivais à la cité universitaire. Au plan politique, ça se passe comme ça, il n'y a rien de direct. Et même, je dirais que pendant les toutes premières années, je fréquentais plutôt des gens, comme par hasard, des gens qui appartenaient au R.P. F. * qui se lançait en 47.

V. \& I.(1) - Il y a des gens qui sont importants pour toi à ce moment-là, des philosophes, des politiciens?

* Rassemblement du Peuple Français. 
M. v. Schendel - Non. C'était plutôt les romanciers, Malraux évidemment - j'avais lu tout Malraux - mais en même temps au fond je n'étais pas très attiré de ce côté-là, Malraux est un des fondateurs du R.P.F., mais le côté formulaire de Malraux m'agaçait prodigieusement.

\section{V. \& I.(1) - Qu'est-ce que tu entends par là?}

M. v. Schendel - C'est une écriture par formule, qui est inévitable. Il me semblait qu'il y avait comme une sorte de tricherie chez Malraux: c'est que cet aspect formulaire de l'écriture lui servait à lui, à figer des énoncés à valeur atemporelle, à valeur quasi métaphysique. Je n'aimais pas ça même si, cependant, au plan politique, il y avait ça, il y avait l'émergence du R.P. F., il y avait tout l'anti-communisme des lendemains de la Deuxième Guerre mondiale. J'étais bien ŝ̂r traversé de tout ça. Je ne pouvais que naître, je crois, dans le moment même où le cerveau comme la peau sont marqués par la chrysalide. C'est peu à peu que... au fait, je ne me suis jamais engagé de ce côté-là, mais il y a eu une séduction très passagère et avant de rencontrer des étudiants communistes ou des étudiants progressistes, il y en avait beaucoup à l'époque, à la cité universitaire en particulier, j'ai rencontré des peintres. Les peintres ont été très importants. Pourquoi les ai-je rencontrés? mais c'est le hasard. Je m'étais lié avec deux d'entre eux, deux Belges: l'un du Borinage, probablement que la métaphore minière dans mes premiers textes lui doit beaucoup, l'autre également du Borinage mais beaucoup moins bon peintre. Ils s'appelaient l'un Émile Hecq, l'autre Tournay. Et je les voyais tous les jours. On mangeait ensemble, on discutait peinture ensemble, ils me montraient tout ce qu'ils faisaient. Par eux, j'avais également rencontré un autre Belge mais qui lui, comme moi, était français. Un certain Jean Claessens, je ne l'ai plus jamais revu depuis, m'avait fait rencontrer d'autres peintres de ses amis, un certain Camus, et nous faisions tout un groupe, moi je n'étais pas peintre mais c'est comme ça que j'ai eu une culture picturale et en même temps une attitude et un comportement d'artiste devant l'existence sociale mais très affichés, très marqués, disons anarchisants. Ça, c'est très important parce que je crois que cette expérience existentielle de comportements anarchisants me poussait davantage en dehors de la chrysalide.

V. \& I. (1) - Pourquoi tu vas en droit et en études politiques, pourquoi ce choix à Paris, est-ce qu'il est fortuit? Pourquoi tu ne vas pas en lettres, en médecine?

M. v. Schendel - J'avais essayé d'entrer à l'École des chartes. Ce n'était pas possible pour je ne sais plus trop quelle raison. Il y avait des examens d'entrée et j'étais sûr d'être recalé.

\section{V. \& I.(1) - Et la philosophie?}

M. v. Schendel - Non. J'étais peu attiré de ce côté-là à l'époque. Mon bagage intellectuel d'enfant et d'adolescent, c'était surtout un bagage d'historien, si je peux dire. Mes lectures étaient des lectures d'historiens. D'historiens du Moyen Âge et d'historiens de la Révolution. C'était surtout ça. 


\section{V. \& I.(2) - Alors pourquoi pas «histoire"?}

M. v. Schendel - Pourquoi pas «histoire» effectivement? Parce que mon père avait pensé - j'étais quand même beaucoup sous l'influence de mon père - il avait pensé à l'École des chartes. Comme ça ne pouvait pas réussir, que c'était trop difficile, j'ai été attiré par ce qui ressemblait le plus à l'histoire; c'était l'économie, c'était la géographie, la géographie politique, la géographie économique avec Pierre George qui était un professeur extraordinaire à l'époque et c'était l'histoire des doctrines politiques et ça c'était "études politiques».

V. \& I.(1) - Et maintenant, puisque tu te sentais plus aristocrate que bourgeois, pourquoi le Parti communiste?

M. v. Schendel - Ce n'est pas une trajectoire linéaire.

V. \& I. (1) - Qu'est-ce que ça veut dire aristocratique pour toi? Est-ce que c'est au sens métaphorique ou propre?

M. v. Schendel - Dans ma biographie sociale si je puis dire, c'est-à-dire l'amont familial, et les alentours de cet amont, effectivement il y avait je crois, c'était presque sous une forme mythologique, mais pas seulement mythologique, il y avait, et ça je l'avais appris dès la plus tendre enfance, du côté maternel, du côté de mes grands-parents qui s'appelaient Levêque, il y avait un mépris souverain de tous ceux qu'ils appelaient les parvenus. Et les parvenus, c'est-à-dire les nouveaux bourgeois, les nouveaux grands bourgeois et ceux qui d'ailleurs à la faveur des deux guerres avaient fait fortune en bénéficiant notamment des commandes allemandes...

\section{V. \& I.(1) - Ton père n'avait pas de rapport avec ça?}

M. v. Schendel - Ah non, mon père était un résistant pendant la guerre. Tous les bourgeois ne se trouvaient pas du même côté quand même, même si par la suite mon père est devenu tout à fait réactionnaire comme cela arrive la plupart du temps dans des conjonctures comme celle-là, la guerre. Non. Mon père était du côté des patriotes, du côté des résistants. Il fabriquait de fausses cartes d'identité, il a fait passer pas mal de gens, enfin, en Angleterre. Les parvenus c'étaient aussi ceux qui historiquement avaient contribué à l'érosion de la première grande bourgeoisie industrielle dont la famille de mon grandpère avait participé. Ce mépris était historiquement bien ancré, tout à fait explicable pour des raisons historiques. Ils avaient été volés, en quelque sorte. Ils le ressentaient comme ça. Puis en même temps, les parvenus c'était ça, mais c'était aussi une attitude, une autre attitude et une autre morale. C'était les grossiers confondus à l'époque avec les vulgaires. Depuis que je vis ici j'ai, au contraire, essayé de faire la distinction entre vulgaire et grossier. Ici nous avons beaucoup de gens vulgaires et nous avons certainement dans la bourgeoisie qui existe, la bourgeoisie québécoise de langue française, nous avons certainement aussi des gens grossiers. Nous n'avons pas dans la bourgeoisie européenne, en tout cas belge ou française, nous avons une grande 
grossièreté, mais nous n'avons pas de vulgarité. La vulgarité c'est le peuple et le peuple est objet de mépris ou de condescendance. L'aristocratie, elle, vient de là; c'est une valeur de l'éducation, c'est une valeur du retranchement, du renoncement, c'est une valeur de l'effacement. On a cette fierté... ça je crois... C'est une valeur qui m'est restée. Toute la sortie de la chrysalide n'a pas fait s'évacuer, n'a pas assuré l'évacuation de toutes les valeurs qui m'avaient constitué. Cette valeur-là est restée. Celle de la fierté. Et la fierté ça consiste, par exemple, à se dire ceci: s'il y a des petits malins qui aiment prendre la place, on les laisse faire: tant pis pour eux, ça ne me touche pas. Et c'est aussi une non-compromission avec le pouvoir. Le pouvoir assumé comme la plupart de nos collègues continuent de l'assumer, de façon assez grossière je dirais, comme s'identifiant ou comme coïncidant avec le pouvoir personnel...

V. \& I.(2) - Mais l'aristocratie s'est compromise avec le pouvoir.

M. v. Schendel - Elle s'est compromise avec le pouvoir.

V. \& I.(2) - C'était le pouvoir...

M. v. Schendel - Je vous parle de cette mythologie, mais cette mythologie qui en même temps n'est pas seulement mythologique, qui a des fondements historiques mais qui est mythologique par rapport à l'aristocratie ancienne qui, bien sûr, était un instrument de pouvoir. Mais l'aristocratie telle que ces grands bourgeois ruinés, ceux que j'ai connus dans mon enfance, telle qu'ils la vivaient, c'est une attitude morale et, je dirais, dans leur cas, qui recoupe l'expérience religieuse.

V. \& I.(2) - La religion c'est aussi le pouvoir?

M. v. Schendel - C'est aussi le pouvoir. Mais il y a les valeurs religieuses telles qu'elles étaient enseignées, en particulier à ces enfants de la classe, c'était une morale de renoncement.

V. \& I.(2) - C'était une façade, une image?

M. v. Schendel - Oui, mais c'est ça aussi qui m'a amené plus tard à reconnaître l'énorme importance de l'idéologie. Elles sont efficaces à leur façade... super-structure. La métaphore du haut et du bas! je veux bien, mais c'est beaucoup plus que ça. Cette façade, elle forme, elle modèle, elle conduit non pas simplement à des comportements individuels mais à des comportements collectifs.

V. \& I. (1) - Revenons à Paris ... tu vas donc t'inscrire assez rapidement au Parti et tu deviens un militant?

M. v. Schendel - Enfin, ça m'a pris quand même quatre ans après la guerre, en 1949.

V. \& I.(1) - C'est le produit de ta réflexion? 
M. v. Schendel - D'une part.

V. \& I.(1) - Et du vécu de 1946 à 1949 à l'Institut d'études politiques et à la faculté de droit?

M. v. Schendel - Oui, et de la rencontre de tous ces gens qui ont contribué à me former. À l'époque, on ne mangeait pas toujours à notre faim, même si notre situation s'était améliorée. Et à la cité universitaire il y avait une jeune femme qui faisait les chambres et qui m'avait pris en amitié, un peu materné en quelque sorte. C'était une ouvrière et elle s'occupait de mes affaires. Un jour, elle m'avait invité chez elle et son mari. À partir de ce moment-là, ça remonte à 1946, toutes les semaines, tous les samedis... C'étaient des ouvriers, des ouvriers qui, eux, avaient une expérience politique et une expérience revendicative et ils m'amenaient chez eux et me faisaient rencontrer leurs copains. Je découvrais tout un monde que même la guerre ne m'avait jamais permis de voir. Je l'avais vu peut-être, mais à travers l'écran social. Le déchirement du manteau guerrier, ou plutôt le déchirement guerrier du manteau social n'avait pas permis de percer cet écran. La classe ouvrière c'était quoi? c'était le peuple, c'était l'inférieur. Or, je découvrais là quelque chose d'extrêmement vivant et qui n'était pas du tout inférieur, au contraire, et qui dans son attitude, disons immédiate, par rapport à moi, au contraire, en tout cas, tenait une position de supériorité puisqu'ils me prenaient en mains et contribuaient à me former. Cela a énormément compté. Jusqu'à mon départ pour le Québec j'ai continué de les voir, jusqu'en 52. C'étaient également des gens qui avaient milité au parti communiste mais comme des "prolos» parisiens souvent peuvent ou pouvaient militer, ils avaient fait la Résistance, ça c'était sérieux, et c'est par la Résistance qu'ils étaient entrés au Parti. Ça aussi, c'était sérieux: le Parti était une force d'organisation, de contestation, de résistance. Ça avait été la principale, pendant la guerre. C'est par ce biais qu'ils étaient venus au Parti. Mais après la guerre ils l'avaient laissé. Et puis bon, un "prolo» parisien est un petit peu "anar». Il y avait une bonne vieille tradition, heureusement en un sens, de l'anarchisme révolutionnaire. Les "prolos » de cette époque étaient jeunes encore, mais ils étaient très marqués, à leur insu parfois, par cette tradition de l'anarchisme révolutionnaire. Et ça, ça me permettait de recouper l'espèce d'anarchisme artistique que je voyais s'afficher chez mes amis peintres. Et je crois que cette espèce de mixte de l'anarchisme individuel et de l'anarchisme révolutionnaire et aussi de ce qu'on a appelé l' «engagement politique», j'ai horreur de ce terme, disons de l'implication politique du côté des communistes, je crois que c'est ça qui m'a permis de faire le pas.

A partir de 1947, il ne faut pas oublier aussi que nous entrons dans la guerre froide: il y a le plan Marshall et il y a de nouveau des préparatifs de guerre. Je rencontre, à travers toutes ces influences, immédiatement ressenties et vécues, partagées, des étudiants membres du parti communiste et qui me font lire, qui me parlent des lectures qu'ils font. Et je me suis mis à lire Marx et Engels. J'ai commencé par les études philosophiques d'Engels, par Ludwig Feuerbach et la fin de la philosophie classique allemande, ensuite j'ai lu... je n'ai pas lu immédiatement le Capital sauf des bribes et surtout les écrits 
polémiques et politiques ou les interventions ponctuelles de Marx telles que Travail salarié et capital, Critique des programmes d'Erfurt et de Gotha. Donc il y a une information à laquelle je commence à être sensibilisé et qui est en contradiction avec toute mon histoire sociale mais qui est en accord avec la poussée hors de la chrysalide que je vis à ce moment-là et qui commence à s'affirmer. Et aussi au plan de l'histoire immédiate, il y a, et ça c'est ce qui me fait adhérer, la signature du traité de l'Atlantique Nord. C'est la signature du traité de l'O.T.A.N. (le 4 avril 1949). C'est le pacte de l'Atlantique. Je suis très révolté, profondément révolté - je me rappelle très bien j'ai 20 ans à ce moment-là, je vais avoir 20 ans - je suis profondément révolté par cette entreprise qui me paraît nettement d'origine américaine, qui me paraît être une entreprise de provocation à l'échelle mondiale qui pourrait, c'est comme ça que je le vois à l'époque, être beaucoup plus dangereuse que le nazisme. L'expérience du nazisme remonte à la surface, et à travers cette remontée à la surface, l'expérience de la pauvreté et de l'humiliation et de la misère de la guerre.

\section{Organiser des formes}

V. \& 1.(1) - Alors là, pendant trois ans, avant de partir pour le Québec, c'est l'histoire de tes vingt ans. Que fais-tu au parti communiste français? Dans la chronologie que nous avons établie, on te voit membre de l'Union nationale des étudiants (l'U.N.E.F.), tu y milites pour la sécurité sociale étudiante, le pré-salaire étudiant et le droit de regard sur la gestion des restaurants universitaires.

M. v. Schendel - L'U.N.E.F. c'est le syndicat étudiant qui existe toujours, qui a eu toutes sortes d'avatars dans ses orientations. Et en principe tous les étudiants en sont ou peuvent en être membres. Ça n'a rien d'extraordinaire, disons que j'y milite mais en quelque sorte à l'extérieur de l'appareil syndical proprement dit. J'y milite en tant qu'étudiant communiste, parce que je suis un étudiant, parce que c'est mon milieu de travail. Je n'ai pas milité dans une cellule ouvrière, je n'étais pas un ouvrier. C'est même contre toute efficacité possible. Je ne suis pas un gauchiste non plus à l'époque. Pas du tout. J'ai toujours lutté contre le gauchisme que je trouve, que j'ai toujours troúvé irresponsable et surtout "mésutilisant» les ressources organisationnelles dans la mesure précisément où, comme on l'a vu dans les années soixante et soixante-dix avec les "mao», ceux qui allaient s'établir en usine faisaient quelque chose qui n'avait pas d'efficacité, qui ne pouvait pas en avoir. Moi je travaillais et je militais dans mon milieu de travail.

V. \& I. (1) - Ce qui est frappant pour l'observateur, c'est qu'il y a trois journaux qui te mobilisent: Clarté, Propositions que tu fondes et Cité libre. Est-ce que ça veut dire que ton action a surtout été une action d'écriture, d'essayiste, de journaliste?

M. v. Schendel - Non. C'était une action d'organisateur. Et c'est par l'organisation que j'ai été conduit et que je relançais cela sous la forme de l'écriture, bien sûr, mais c'était une écriture de combat, de lutte. Cité libre 
c'était le journal des étudiants communistes de la cité universitaire. Peut-être que cela existe encore, je ne sais pas? J'étais un organisateur, c'est-à-dire comme tous les communistes d'ailleurs, le communiste n'est un militant que parce qu'il organise, c'est sa fonction. Organiser quoi, organiser qui, organiser quelle forme? - on organise des formes...

\section{V. \& I.(1) - Lesquelles as-tu organisées?}

M. v. Schendel - Des pétitions, ventes de journaux, organisation de campagnes de signatures: par exemple, l'appel de Stockholm dont nous avions, avec nos amis du Mouvement de la paix, la responsabilité pour tout le territoire de la cité universitaire et au-delà. Mais c'était surtout nous les organisateurs. S'il n'y avait pas eu nous les organisateurs, il n'y aurait pas eu de Mouvement de la paix. Organisation du financement: souscriptions, organisations de petites fêtes pour relancer le financement. Et à travers le financement trouver de nouveaux sympathisants, élargir le réseau des sympathies, qui à l'époque étaient quand même assez nombreuses, et des adhérents éventuels. Faire en somme la même chose qu'on avait faite avec moi. Et très très vite, dès 1950 , un an, un an et demi après mon entrée au parti communiste français, je deviens secrétaire de cellule. Donc j'ai la responsabilité principale, en tant que secrétaire de cellule, de l'organisation du travail sur tout ce grand territoire - c'est un très grand territoire la cité universitaire de Paris même à cette époque - ... nécessité d'entretenir des contacts suivis et réguliers, très réguliers et très fréquents, avec l'ensemble des pavillons de la cité universitaire, donc avec l'ensemble des étudiants étrangers qui s'y trouvent et des étudiants français: les étudiants étrangers parmi lesquels il y a beaucoup d'étudiants coloniaux, comme on les appelait à l'époque. C'étaient des étudiants coloniaux, ils venaient des colonies. À une époque où nous sommes en train de former le Mouvement de la paix, eux arrivent avec leurs expériences d'étudiants colonisés, de peuples colonisés et avec leur expérience des nécessités d'organisation de la lutte contre le colonialisme qui ne recoupe pas exactement les cases du Mouvement de la paix. C'est donc, de ce point de vue-là, un terrain splendide, extraordinaire parce que nous avons le monde en petit. Notre théâtre c'est le monde à la cité universitaire à cette époque-là.

V. \& I.(1) - Ça c'est très clair, alors: organisation, secrétaire de cellule...

M. v. Schendel - Et organisation également de la partie revendicative de notre action. Et ça, c'était important pour assurer le contact vivant, dynamique avec les autres étudiants qui partageaient le même sort que nous, même s'ils n'avaient pas les mêmes orientations que nous. Par exemple le restaurant universitaire où la bouffe était infecte. Il fallait se battre pour avoir un contrôle sur la gestion dé ce restaurant. Et nous sommes parvenus à assurer un certain contrôle, par le biais, à la cité universitaire puisque c'était notre territoire, par le biais de notre organisation syndicale qui était distincte évidemment du parti communiste et très souvent anti-communiste, mais où nous étions présents. Alors, c'était tout ça l'organisation. 
V. \& I. (1) - Et là-dessus se greffait sûrement une activité intellectuelle propre à l'époque, qui était d'orientation bien sûr communiste...

M. v. Schendel - Mais c'est directement une activité intellectuelle dans la mesure même où c'est une production de formes. Nous inventons des formes même si nous ne voyons pas sur le coup que très souvent ces formes que nous inventons ont déjà été inventées par l'ensemble du mouvement communiste et parfois pas toujours pour le mieux.

V. \& I. (1) - Mais que lis-tu à cette époque, vers 1950 , au moment où va commencer le nouveau roman, au moment où Malraux, Sartre et les existentialistes sont prédominants sur la scène? Est-ce que tu es complètement en dehors de la scène littéraire?

M. v. Schendel - Oui. Complètement en dehors. Je lis encore une fois de temps en temps Sartre mais je me rappelle que les Mains sales m'avaient vraiment dégoûté. Et ce que je lis, c'est surtout de la littérature communiste et des poètes, beaucoup beaucoup de poètes, je lis Éluard. Je lis Apollinaire. Je lis Max Jacob. Je lis Aragon que je n'aimais pas tellement comme poète, je le préférais comme romancier. Et je lis alors beaucoup d'ouvrages publiés par les presses du Parti, par les Éditions sociales et par les Éditions de la Nouvelle critique. Je suis abonné à toutes ces revues. Je lis toutes sortes de journaux: Tribune internationale qui a disparu aujourd'hui, qui était un excellent journal.

V. \& I.(1) - Dans tes souvenirs, ce qui prédomine ce sont donc les poètes?

M. v. Schendel - Les poètes et la lecture politique.

V. \& I.(2) - Et les poètes soviétiques?

M. v. Schendel - Il y a Maïakovski que je lis à ce moment-là, que je découvre mais là ça recoupe très directement mon inscription politique. Je découvre aussi ce poète turc, Nazim Hikmet.

V. \& I.(1) - Est-ce que tu lis les écrivains français qui ont été très attirés par le P.C. ou en tout cas par le communisme, comme Gide, qui voyage, qui se convertit... et qui se repent!

M. v. Schendel - Oui, j'avais lu déjà Gide. Ça c'était dans ma période de sortie de la chrysalide à la fin de la guerre et puis après. Non je lis assez peu Gide à ce moment-là. Je ne lis plus Malraux. Ça aussi c'est réglé. Je lis un petit peu Sartre. J'ai fini de lire Camus.

V. \& I.(1) - Camus avait eu une certaine importance pour toi?

M. v. Schendel - Oui. Jusqu'en 47-48. Je découvre alors des jeunes poètes comme Henri Pichette.

V. \& I.(1) - Tu l'as connu personnellement? 
M. v. Schendel - Je l'ai connu mais plus tard ... je lis alors quantité d'articles et d'ouvrages. Je lis Lénine. Je lis les théoriciens... en même temps je poursuis des études en sciences économiques.

V. \& I.(1) - Qu'est-ce que t'apportent tes études en droit puisque tu vas finir par obtenir une licence en droit tout en faisant mille autres choses?

M. v. Schendel - C'est d'ailleurs à partir du moment où j'ai su devenir vraiment un organisateur que j'ai pu régler ce problème des études et être efficace. Et, alors là, ça été très vite. Ce qui me passionne alors dans le droit, c'est l'histoire du droit qui recoupe d'assez près, du moins selon l'interprétation que j'en fais à l'époque, l'histoire des techniques. Le rapport entre les techniques par exemple d'assolement, les techniques agraires et le développement des droits de propriété. Et là, je retrouve mes anciennes préoccupations, mes anciennces passions pour l'histoire, ce qui me permet d'asseoir l'histoire du droit sur d'autres bases que celles du développement de normes intemporelles. Elles sont au contraire très temporalisées et en même temps ça me permet de voir le décalage qu'il y a, et ça je le découvrirai beaucoup plus tard. Le droit a été beaucoup plus vivifiant à partir du moment où j'ai cessé d'en faire, c'est-à-dire ici à partir du moment où je vais essayer de mettre ensemble, de composer à des niveaux différents les formes stables du discours et les formes politiques et économiques étroitement conjoncturelles de la réalité sur laquelle s'asseoit cet énoncé juridique comme l'adage ou la loi. Et ça, ça me mènera alors évidemment du côté de la réflexion sur l'institution.

V. \& I. (1) - Mais il n'est pas question que tu deviennes avocat à ce moment-là!?

M. v. Schendel - Non, pas du tout. Ça ne me plaît pas, ça ne me tente pas. C'est une espèce de goût intellectuel, que je résume ainsi, que j'ai pour le droit et encore plus pour les sciences économiques. Alors je lis énormément en sciences économiques et c'est ce qui m'a permis beaucoup plus tard, dans les années soixante, d'être journaliste économique ici.

\section{Aimer partir}

V. \& I.(1) - Et alors au moment où tu t'inscris en scolarité de doctorat en sciences économiques il y a cette rupture: tu quittes la France pour le Québec en octobre 1952 en compagnie d'Adèle Lauzon que tu as connue à Paris. Est-ce qu'alors cet autre choix, aussi capital peut-être que celui que tu fais à vingt ans, s'explique de manière simple? Est-ce que c'est une histoire d'amour qui t'amène au Québec, est-ce que c'est autre chose?

M. v. Schendel - C'est une histoire d'amour et c'est aussi autre chose. Je fais la connaissance d'Adèle Lauzon en qualité d'organisateur. Je suis membre, n'oublie pas, du parti communiste et j'ai des responsabilités dans le Parti. Je suis responsable du développement de la campagne pour la paix dans le milieu étudiant, à la cité universitaire, et pour l'ensemble du quatorzième arrondissement et auprès de la fédération des étudiants. J'ai dit tout à 
l'heure que, du fait de l'exercice de ces responsabilités, j'étais amené à connaître à peu près tout le monde à la cité universitaire et tous les milieux étrangers. Il y avait un pavillon que nous n'avions pas encore réussi à pénétrer: c'était le pavillon canadien. Un autre où nous avions très peu de contacts, c'était le pavillon américain: celui-là on le tenait plutôt à l'écart. Le pavillon canadien au contraire nous intéressait d'autant plus que c'était en Amérique du Nord, voisin des États-Unis, et d'autre part nous savions tout de même qu'il y avait des Canadiens français et que donc, culturellement, il n'y avait pas de raisons de se tenir à distance d'eux. Et à l'occasion de la campagne de signatures à l'appel de Stockholm, mon frère qui était français comme moi et qui habitait également la cité universitaire avait fait la connaissance d'une jeune Canadienne française qui lui avait fait rencontrer une de ses amies qui était Adèle Lauzon. Il me présente par hasard Adèle Lauzon, on bavarde un petit peu et je découvre qu'elle a des orientations très intéressantes pour quelqu'un comme moi, du point de vue de mon plan politique, qui était très sensibilisée précisément à toute l'organisation du travail contre la guerre, contre le danger de guerre. Je lui parle de l'appel de Stockholm, je lui demande si elle peut se charger de faire signer ça au pavillon canadien. Le soir même elle revient avec une liste complète, elle avait fait signer à peu près tout le monde. Ça, c'était absolument extraordinaire, c'était même peut-être un petit peu inquiétant parce qu'on pouvait se demander quelles étaient les motivations. Je commence à ce moment-là à découvrir le milieu canadien, canadien-français - c'était essentiellement un milieu canadien-français - et je fais la connaissance de plusieurs d'entre eux. Ainsi, un peu plus tard j'ai fait la connaissance d'Hubert Aquin à Paris. Et je m'aperçois que sur le plan politique ils ont des attitudes, je dirais très robustes et saines - ils n'y vont pas par quatre chemins - et en même temps un petit peu primaires, sans histoire politique derrière eux et très souvent ils réagissent par la simple révolte. Mais pourquoi pas? Moi aussi j’avais réagi par la révolte. Ça peut être intéressant. Et de fil en aiguille, je propose à quelques-uns d'entre-eux -à cinq d'entre eux, dont Adèle Lauzon - de s'inscrire au parti communiste mais en faisant très attention. Ils ne peuvent pas être inscrits au fichier des membres parce que ce serait dangereux pour eux. Il ne faut pas oublier que c'est tout de même la période du "maccarthysme» et ensuite ils rentrent au Canada et ils peuvent avoir des ennuis. Mais je leur propose, en accord avec la direction du Parti, de former une cellule, mais séparée. Et je rencontre l'homme d'affaires de Jean Lurçat, grand peintre et tapissier, qui était membre du Parti et qui habitait le quatorzième arrondissement, qui avait son atelier là et nous nous organisons, de façon à avoir des rencontres périodiques dans l'atelier de Jean Lurçat. Alors je suis là, comme le répondant du parti communiste français, et il y a ces cinq étudiants canadiens-français, québécois.

V. \& I.(1) - Te souviens-tu des noms?

M. v. Schendel - Oui, mais je ne les dirai pas. Je ne peux pas en tout cas conter une expérience que $j$ 'ai vécue, $j$ 'ai dû faire très attention moi-même par la suite, je ne peux pas à la légère dévoiler des noms sauf celui d'Adèle Lauzon parce que c'est connu. 
V. \& I.(1) - Même quarante ans plus tard, tu ne peux pas?

M. v. Schendel - Non. Ça, c'est une expérience qu'on apprend très jeune et qui reste là en permanence d'autant plus que j'ai encore découvert en 1981 à quel point il était difficile de percer des résistances notamment policières et politiques du très haut appareil bourgeois pour lequel elles fonctionnent. Il a fallu quand même que j'attende jusqu'en 1981 pour avoir la citoyenneté canadienne, ce n'est pas par hasard, il faut faire attention.

\section{V. \& I.(1) - Comment arrives-tu au Québec?}

M. v. Schendel - C'est pas simple, comme je le disais. D'une part, je fais connaissance avec Adèle Lauzon, et il y a parallèlement à ça, moi qui n'avais aucune espèce d'expérience - oui j'avais été amoureux comme tout le monde quand j'avais 17 ans (j'avais rencontré une jeune bordelaise que j'aimais d'un amour très canonique) mais c'est ma première expérience $d$ 'homme - je la fais passé vingt ans - d'homme amoureux. Et c'est avec une Québécoise et c'est une révolution, c'est une révolution pour moi. Et c'est une révolution également qui me pose des questions, qui me met légèrement en porte-à-faux par rapport à l'appareil communiste et, là, je commence à prendre des distances parce que cette histoire d'amour, qui en est une, n'est pas acceptée dans toutes ses implications par l'appareil du Parti.

\section{V. \& I.(1) - Tu te retrouves au collège?}

M. v. Schendel - Je me retrouve au collège d'une certaine façon. Je me retrouve avec des censeurs, y compris l'un de mes meilleurs amis qui était un camarade avec qui je travaillais à la cité universitaire, lui aussi d'origine belge mais français, Henri, qui fait un peu comme le grand frère, le grand frère tel que je l'avais déjà connu et qui avait été le substitut du père et qui, lui et d'autres membres responsables de la section du quatorzième arrondissement du Parti, disent: non, il jaut faire très attention. D'accord vivez ensemble, ça ne nous regarde pas, mais faites très attention, elle est canadienne et elle peut vouloir retourner chez elle. Effectivement le problème s'est posé, on a dû se marier, pour des raisons que je n'ai pas besoin... de toute façon on vivait ensemble, il a fallu se marier étant donné qu'il n'y avait pas d'avortement et on était dans une condition financière, pas elle mais moi, très précaire. Je n'avais pas un sou. J'avais un petit travail: c'était les Amitiés francopolonaises qui ne payait presque rien, il fallait vivre et elle était également, disons, très dépendante affectivement, je dirais psychiquement, donc très fragile et très dépressive et comme les conditions étaient vraiment mauvaises, je voyais bien qu'elle avait besoin d'une plus grande sécurité en revenant chez elle. Et c'est à ce moment-là que j'ai dû accepter d'autant plus qu'il y avait des problèmes avec sa famille à elle. Son père acceptait très mal, parce que les gens avaient parlé: elle avait rencontré un communiste! Pour lui c'était horrible, scandaleux: sa pauvre et chère grande fille était en danger d'excommunication. Pour toutes ces raisons-là, je lui avais offert de venir au moins apaiser les choses, le temps d'avoir le bébé et puis on rentrerait en France. Le mariage s'était fait à Paris. Mais aussi pour toutes ces raisons-là, les cama- 
rades communistes disaient: Bon ben voilà, on t'avait prévenu, voilà ce qui s'en vient. Il faut pas que tu ailles aú Canada, c'est un pays fasciste... . J'étais assez informé de la politique canadienne pour savoir que ce n'était pas un pays fasciste. Et que c'était pas les États-Unis.

\section{Vivre: Montréal 1950}

\section{V. \& I.(1) - C'était Louis Saint-Laurent qui était Premier Ministre.}

M. v. Schendel - Oui. C'était un pays très conservateur, pro-américain d'accord, mais enfin c'était pas aussi simple que ça. Et je me suis rendu compte qu'il y avait donc une forme d' "engagement" politique qui risquait de devenir une servitude, dans la mesure où la vie des contradictions entre l'affectif et le politique, entre l'amour et le politique, et donc la mise à distance, la spatialisation de ces scènes qui ne se recoupent pas mais qui doivent pouvoir être vécues ensemble, cette contradiction n'était pas reçue, n'était pas acceptée. Et ça, ça m'a posé des problèmes par rapport à ce que c'était que l'organisation communiste. Mais à l'époque, sur le moment et pendant plusieurs années, vivant ici, m'interdisant de participer à tout mouvement politique, parce que pour moi un communisme ne pouvait être que national, et je devais donc rentrer en France, il n'était donc pas question pour moi d'avoir quelque activité que ce soit ici, dans les débuts en tout cas. En même temps j'étais bourré de remords, je me sentais très coupable parce que je ne pouvais pas retourner en France. Et je pouvais d'autant moins retourner en France, et là vraiment c'était l'impasse, que ma compagne de l'époque n'acceptait plus malgré le contrat engagé entre nous, acceptait de moins en moins une fois ici - et à un certain moment ça a été radical, ça a été non - n'acceptait plus de retourner en France avec moi. Elle voulait demeurer au Québec. Alors là, moi, je me retrouvais coincé, paumé.

V. \& I.(1) - Est-ce que l'enfant était né?

M. v. Schendel - L'enfant était né, les deux enfants étaient nés. Nicolas et Vincent.

V. \& I.(1) - Tu as une famille à faire vivre et ça va prendre plusieurs années avant que tu aies un travail rémunérateur et stable. Alors tu vis d'expédients de 1952 à 1955? C'est visible puisque tu es employé de garage de 1952 à 1953; vendeur de journaux, de porte en porte, il ne s'agit sûrement pas de journaux communistes! de 1953 à 1954; tuteur à domicile en 1953-54 et colporteur. En 53 tu commences à enseigner au Lycée Valéry où tu resteras jusqu'en 1959. Aussi en 1953-1954 tu collabores à l'hebdomadaire culturel l'Autorité du peuple.

M. v. Schendel - C'est beaucoup de travail à l'époque, surtout pendant l'année 54-55 où je suis toujours professeur à la leçon - ça, c'est après l'expérience de colporteur - je suis professeur à la leçon au Lycée Valéry mais donc payé à la leçon et pas payé pendant les cinq ou six mois de vacances. Il fallait donc que je prenne énormément de tâches d'enseignement 
pour pouvoir vivre un peu et mettre un peu d'argent de côté pour l'été mais .pas suffisamment, enfin à l'époque on était payé cinq dollars de l'heure pour des charges d'enseignement allant jusqu'à quarante élèves par classe, c'était énorme, il y avait du travail de préparation et c'était à tous les cycles. C'était au secondaire et c'était également au collégial. Et c'était le français, l'histoire du français, la grammaire, l'histoire de la littérature française, l'histoire de la littérature canadienne-française, que j'apprends à ce moment-là, que je découvre aussi, l'histoire, la géographie, le droit commercial et histoire de l'art. Trente heures par semaine de cours puis je tombe malade, très gravement.

\section{V. \& I. (1) - Est-ce que c'est la pleurésie qui revient?}

M. v. Schendel - Non. C'est une maladie des reins doublée d'une double pneumonie. Une infection rénale, la pyélonéphrite.

V. \& I. (1) - Et tu es hospitalisé à ce moment-là?

M. v. Schendel - Non, un brave et bon médecin qui comprend bien ma situation, qui veut me faire payer le moins possible - il n'y a pas d'assurance sociale et je suis absolument incapable de payer l'hôpital - trouve le moyen de me soigner à domicile. Pendant trois semaines.

\section{V. \& I.(1) - Et l'écriture?}

M. v. Schendel - D'abord j'écris depuis quand même longtemps, même si je n'ai pratiquement rien publié sauf des articles de journaux, des études bien documentées mais qui sont sous forme d'articles de journaux. J'écris quand même depuis plusieurs années à cette époque-là : en 52-53. Je fais la connaissance par les amis de ma compagne, de jeunes journalistes, notamment un journaliste français, Jean Vincent: un journaliste québécois Noël Pérusse, ils travaillent avec Jean-Louis Gagnon qui, à l'époque, a la réputation d'un très grand progressiste - qui n'était pas tout à fait fausse - même communiste - ce qu'il n'était pas absolument pas - mais ce sont des gens qui réagissent très fortement et intelligemment à l'espèce de chape de plomb qui pèse sur l'ensemble des moyens de presse qu'on appellera plus tard les médias: à Radio-Canada, dans la presse écrite et dans la presse parlée. Et un journal, un petit hebdomadaire de région - de Saint-Hyacinthe - qui s'appelait l'Autorité tombe en panne, le titre est disponible et moyennant une petite mise de fond, qui est vraiment très peu de choses, ce journal est racheté mais son titre, son nom, transformé. On ajoute à l' "Autorité»: «du peuple». C'est dire dans quel sens se dirigeaient ces jeunes gens.

\section{V. \& I.(1) - Qui est l'initiateur? C'est Gagnon toujours?}

M. v. Schendel - L'initiateur, l'organisateur, pas le financier, le bailleur de fond, mais l'organisateur c'est Jean Vincent qui a une forte expérience de journaliste et aussi une expérience historique assez considérable: la guerre du Viet-Nam, la sale guerre; il a appris beaucoup de choses sur le terrain, il n'est 
pas devenu un ancien colonialiste, au contraire il a appris sur place ce que c'était le colonialisme. C'est un type, excellent journaliste qui garde tout de même ses distances par rapport à toute forme d'inscription politique. Et donc il lance cette entreprise et il me demande si moi ça m'intéresse de collaborer et je collabore. Mais à ce moment-là, en même temps, je suis enseignant: c'est une expérience nouvelle que j'acquiers ici au Québec et qui va m'être très précieuse. C'est au Québec que je suis devenu un enseignant, je ne le serais peut-être pas devenu en France. Je le deviens au Québec et je le deviens par l'accueil qui m'est fait - très difficile mais quand même c'est un accueil qui m'est fait - dans un lycée laïque, c'est-à-dire un lycée qui est en rupture de ban avec les collèges classiques traditionnels, les collèges religieux. Et ce travail dans un milieu laïque, c'est le début des expériences éphémères, à l'époque, de lycées laïques à Montréal : il y en a deux, le Lycée Corneille et le Lycée Valéry. Cette expérience-là nous met à même de passer en revue de façon très critique le matériel pédagogique dans ces établissements d'enseignement secondaire et collégial. En outre, $j$ 'ai eu à faire l'expérience en même temps de la suppléance à la Commission des écoles catholiques d'ailleurs ça n'a pas duré très longtemps parce que j'étais incapable de dire les prières et le principal de l'école se plaignait... Tout ça évidemment me permettait de faire du travail encore une fois à partir de l'organisation qui était alors la mienne, l'organisation pédagogique. C'est en tant qu'organisa'teur pédagogique que j'ai été amené à écrire. Et donc j'ai publié toute une série d'articles sur les manuels déjà là - ça va m'être très utile par la suite -les manuels que j'avais à utiliser en classe. Manuel de latin, de grec, d'histoire, de littérature. Et puis, il y a eu peut-être encore quelques autres collaborations à l'Autorité du peuple, mais la plupart du temps c'était gratuit. Ils étaient tout le temps incapables de payer. J'ai reçu une fois en deux ans un chèque de vingt-cinq dollars pour un article.

V. \& I.(1) - Ce qui devient décisif semble-t-il, en tout cas quand on regarde ton curriculum, c'est ton entrée à Radio-Canada. On sent qu'il y a quelque chose d'autre qui se passe.

M. v. Schendel - Comme scripteur, jamais comme salarié...

V. \& I. (1) - Il y aura là une continuité assez importante. Radio-Canada, O.N.F. bientôt...

M. v. Schendel - Je voudrais signaler tout de suite... d'après cette récapitulation que l'on fait, je ne sais pas dans quelle mesure elle est intéressante, il y a en tout cas une chose que ça permet de voir, c'est que les conditions dans lesquelles je travaille aujourd'hui n'ont rien en commun, absolument rien en commun, - pour moi, c'est la vie dure, elle n'a rien en commun avec l'expérience de travail et de vie molle, gâtée, de la plupart de ceux avec qui je suis appelé à travailler à Radio-Canada. Je pourrais donner des noms...

V. \& I. (1) - Pourquoi Aquin t'invite-t-il tout à coup à Radio-Canada? Est-ce en souvenir de cette amitié? Vous vous connaissiez déjà à Paris? 
M. v. Schendel - Nous nous connaissions déjà à Paris, oui. Je le retrouve dans le milieu montréalais pour les mêmes raisons que je l'avais trouvé dans les milieux d'étudiants québécois à Paris, parce que c'était un ami d'Adèle. Mon passeport, essentiellement au début, dans les milieux québécois intellectuels ou journalisțiques, c'est Adèle, au début bien sûr, ça ne peut être que ça. Ça posait d'ailleurs déjà un certain nombre de problèmes: je tenais tout de même à affirmer mon autonomie. Il faut dire aussi qu'Hubert Aquin est un personnage... mes premiers contacts avaient été, je ne dirais pas froids, ils avaient été ombrageux.

\section{V. \& I.(1) - Ả cause d'Adèle Lauzon?}

M. v. Schendel - À cause de l'amie d'Adèle dont il était fiancé, et puis j'aimais beaucoup cette amie, et je crois qu'Hubert Aquin était jaloux de moi, enfin passons... Il y avait autre chose chez Hubert Aquin. Il y avait une très grande curiosité, une curiosité intellectuelle, mais pas seulement intellectuelle, une très grande curiosité par rapport à une multiplicité de formes de vie. En ce sens, je dirais qu'Hubert Aquin était peut-être, il me semble, si je peux employer ce terme banal et un peu vain, était plus courageux que la majorité des autres et il avait tout de même une expérience plus ancrée et diversifiée et plus internationalisée que la plupart des gens de sa génération, des jeunes intellectuels de sa génération, ceux avec qui par la suite j'ai fondé Liberté et qui ont continué de rester avec Liberté. Alors je dirais que cette curiosité multiple d'Hubert Aquin et aussi le fait qu'il voyait bien que j'avais énormément de difficulté à vivre, à travailler, comme on déroulait le tapis rouge et qu'on lui faisait une place en or à «Radio-Collège» comme réalisateur, à l'époque c'était tout à fait prestigieux être réalisateur à «RadioCollège", et bien il m'avait offert de collaborer aux émissions, à Carrefour de l'Histoire de «Radio-Collège».

V. \& I.(1) - Quel était ton rôle?

M. v. Schendel - Scripteur, je montais toute la documentation. Il m'avait confié deux émissions en 55, l'une sur l'histoire du mouvement ouvrier au $\mathrm{XIX}^{\mathrm{e}}$ siècle, l'autre sur la question d'Extrême-Orient.

V. \& I.(1) - Enfin tu te retrouvais dans tes cordes, tu revenais à l'histoire et tu revenais au fond à tes préoccupations politiques?

M. v. Schendel - Exactement. Mais politiques au sens large, et en tant que vulgarisateur historien.

V. \& I. (1) - Mais ce qui est drôle, c'est qu'en même temps tu fais des émissions pour enfants, dans cette période, entre 55 et 58 tu vas même écrire des chansons et des contes pour la série du Pirate Maboule. Pourquoi?

M. v. Schendel - C'est un peu plus tard, de 56 à 58 . Mais auparavant... J'écrivais, je n'avais jamais cessé d'écrire depuis au moins 1947 et ici également, un temps, Adèle Lauzon s'était vu confier la direction d'un mensuel 
qui s'appelait la Revue populaire qui tirait à vingt mille, ving-cinq mille exemplaires. Elle était très mal payée pour ça. Mais, enfin, elle était la rédactrice en chef, en fait l'unique rédactrice et moi aussi je collaborais à ça. C'était des textes qui n'étaient pas payés. Je signais Michel Levesque et j'avais publié de petits contes et là je découvrais autre chose. Et j'aimais beaucoup les enfants, c'est aussi bête que ça, et j'avais envie d'écrire à leur intention et le débouché s'est offert, je ne sais plus très bien... ah oui par l'intermédiaire de Guy Maufette dont j'avais fait la connaissance.

V. \& I. (1) - Et qu'est-ce qui t'amusait comme sujets pour enfant? Tu exploitais les légendes?

M. v. Schendel - Les légendes, des contes déjà existants mais que je réaffabulais de façon très libre. J'avais écrit notamment pour la télévision une série de contes qui s'appelaient les Aventures de Cadet Roussel. Alors c'était Cadet Roussel mais c'était un tout autre Cadet Roussel et qui passait par des histoires tout à fait farfelues mais aussi farfelues que ce que la forme proverbiale de la chanson connue en dit de Cadet Roussel sauf que, si tu veux, j'étendais dans le récit le caractère débridé des aventures de Cadet Roussel, le caractère surréaliste. J'étais très surréalisant. Ça m'amusait beaucoup et puis ça avait été très bien reçu, on m'en avait commandé d'autres. J'ai d'ailleurs conservé tous ces textes-là. Je ne les ai jamais publiés autrement, enfin il y a cette forme de publication. Ça m'avait beaucoup intéressé. Ça m'a fait découvrir aussi une autre forme, un développement de l'écriture poétique. Et c'est comme ça également que j'ai été demandé l'année suivante pour écrire les textes de la série du Pirate Maboule que j'ai assurée durant deux ans.

V. \& I.(1) - Et ensuite tu continues comme chroniqueur cette fois, critique, à compter de 1956, pendant deux ans, à la revue des Arts et des Lettres de Radio-Canada?

M. v. Schendel - Oui, plus toutes sortes de textes, de séries sur les poètes et aussi...

V. \& I.(1) - La poésie chinoise?

M. v. Schendel - Ah oui, la poésie chinoise. Ça, ça a été une très belle expérience.

V. \& I.(1) - Au service des émissions éducatives et culturelles?

M. v. Schendel - Avec la sœur de Jean Martenot qui avait composé une trame musicale pour l'émission que j'avais préparée sur la poésie chinoise et c'était très très beau.

Et puis aussi un peu plus tard une série, la première série qu'on m'accordait en tant que telle, une série de treize émissions, de treize demi-heures avec «les Personnages en liberté» un peu la mise en parallèle de différents avatars du même mythe littéraire: par exemple Don Juan, sous diverses versions, espagnole, française, anglaise. 


\section{La poésie et nous}

V. \& I.(1) - En tout cas, ce qui est significatif là, c'est que dans ces annnées 1955-56-57-58, et jusqu'à 1960, tu t'affirmes beaucoup plus comme critique littéraire et comme essayiste, mais sans rien publier avant la Poésie et nous (ce qui vient en 1957). J'aimerais m'arrêter à la Poésie et nous mais je constate au passage que tu exploites un vieux fonds quand tu parles de Malraux, peut-être aussi Diderot, Alberti même...

M. v. Schendel - Non, Alberti, je l'ai découvert ici, je ne le connaissais pas avant.

V. \& I. (1) - Sartre et Camus en tout cas, Romain Rolland mais aussi la poésie québécoise et canadienne-anglaise avec des traductions qui vont venir en 1957. Et tout à coup en 1957 il y a ce titre de la Poésie et nous. Alors là, tu t'affirmes comme poète donc une année avant de publier Poèmes de l'Amérique étrangère. Il y a quelque chose qui commence à prendre forme.

M. v. Schendel - Il y a deux tendances qui sont en complémentarité je crois. D'une part, ce développement de l'écriture est dans le prolongement de mes activités de pédagogue qui est la forme d'organisation que je pratiquais à ce moment-là. La forme d'organisation, pour moi, c'est énorme. Un travail intellectuel n'est pensable, n'est encore pensable que comme la grande organisation, c'est-à-dire l'invention des formes, pour moi c'est le propre même du travail intellectuel. Par conséquent, l'écriture, en ce sens, elle est tout simplement dans le prolongement, et j'avais lu quand même Gramsci, qui m'avait beaucoup séduit et énormément influencé, qui est un penseur précisément de l'intellectualité organisée et de l'intellectualité organisationnelle.

V. \& I.(1) - Quand lis-tu Gramsci, en 1950 ?

M. v. Schendel - Oui, déjà avant, en 1949. Ca serait, disons, une chose qu'il faudrait noter : c'est un prolongement de l'enseignement et un prolongement de cette forme d'activité organique et organisationnelle, d'une part. Et d'autre part, il y a le statut même de l'écriture tel que je le vis. L'écriture me devient d'autant plus accessible qu'elle correspond en même temps à une exclusion. Je suis exclu en pratique: de la société québécoise, de la société canadienne; je suis dans la marge et je suis en exil. L'écriture est une expérience de l'exil. Et c'est comme ça que je parviens, aussi le hasard aidant - mais bien sûr les hasards ont été organisés, sollicités - je parviens à développer l'écriture jusqu'au point de la publication et ça va devenir mon métier, mais pas mon métier exclusif parce qu'il y a toujours l'autre versant, l'autre complément : les tendances organisationnelles. L'écriture pour moi ne peut pas être pensée, en dehors de ça. Et c'est aussi pourquoi je ne peux la concevoir, et encore ṕlus l'écriture politique, en dehors de la référence, c'est-à-dire les références historiques.

V. \& I.(1) - Ainsi la Poésie et nous, c'est un discours manifestaire annoncé par le titre et auquel tu participes. Quel est pour toi le sens de cette publication 
en 1957? Ça fait cinq ans que tu es là, tu as attendu longtemps en tout cas... c'est très progressivement que tu te révèles comme un poète.

M.v. Schendel - Au fond le travail de radio et le travail de télévision m'ont quand même beaucoup aidé...

V. \& I.(1) - Non, mais poète au sens traditionnel qui renvoie à un genre... dans ton curriculum, c'est la Poésie et nous qui tout à coup sert de révélateur, est-ce que c'est juste ou pas?

M. v. Schendel - C'est juste. Révélateur oui et non, je n'ai jamais cessé depuis 47 , encore une fois, d'écrire des poèmes.

V. \& I.(1) - Mais public, des manifestations publiques?

M. v. Schendel - Pour des raisons que je viens de dire, c'est l'exil, c'est la forme même, la forme discursive de l'exil, mais de l'exil doublé de l'exclusion politique et en même temps c'est tout à fait autonome, c'est autre chose. Je vis et j'essaie d'articuler cette tension du même et de l'autre, du prolongement de l'exclusion dans le discours, mais en même temps de l'autonomie de l'autre discours qui a ses propres exigences, ce qui me permet également, compte tenu des expériences politiques passées, de tenir à distance le politique de façon à mieux pouvoir l'infléchir éventuellement par l'écriture. Mais alors, en même temps, ça se présente autrement. Je m'étais rendu compte, encore une fois au plan de mon expérience existentielle que, puisque je ne pouvais pas rentrer en France, il fallait que je prenne le taureau par les cornes si je peux dire - le taureau c'était le Québec - et donc que je m'applique à connaître... Et je me suis appliqué systématiquement à passer en revue toute la littérature, toute la littérature telle qu'elle était disponible à l'époque, mais enfin tout de même! J'ai passé en revue les lettres canadiennes-françaises du $\mathrm{XIX}^{\mathrm{e}}$ siècle, les poètes surtout mais aussi les romans, et $\mathrm{du}^{\mathrm{X}} \mathrm{XX}^{\mathrm{c}}$ siècle. Par exemple j'ai été le premier à parler de Jean-Aubert Loranger.

V. \& I.(1) - Comment as-tu fait cet apprentissage? Tout seul en bibliothèque, avec des amis?

M. v. Schendel - En bibliothèque. Parce que pour la préparation de mes séries, de mes émissions, je travaillais quotidiennement en bibliothèque, à l'époque à Saint-Sulpice (aujourd'hui la Bibliothèque nationale), et à la bibliothèque de Radio-Canada. À Saint-Sulpice j'avais de bonnes conditions de travail et puis il y avait un fonds très intéressant de Canadiana.

\section{V. \& I.(1) - Et alors la Poésie et nous, là à l'Hexagone?}

M. v. Schendel - Donc il y a cet attrait volontaire au début, et ensuite qui devient assez passionné, pour le fonds québécois. Et je rencontre à ce moment-là les gens de l'Hexagone. D'abord Hélène Pilote que j'avais rencontrée au moment où se fondaient les Éditions de l'Hexagone, en 1953, elle était l'une des six de l'Hexagone, et ensuite un peu plus tard Gaston Miron parce qu'encore là par le biais de mon enseignement, on avait parlé du travail 
que je faisais et un type qui organisait une auberge de jeunesse m'avait invité à aller donner une conférence, faire un séjour, parler avec les hébergés et Gaston Miron était là et nous sommes devenus très amis. Et c'est lui qui m'a fait découvrir... Gaston Miron a beaucoup compté à ce moment-là pour moi, par la suite moins, je lui montrais les textes, les poèmes que je faisais. Dixit Miron: ce qui est important pour toi, c'est précisément l'expérience de l'exil, c'est l'écriture de l'exil. Et c'est à ce moment-là que vraiment j'ai pu faire le saut, quand j'ai été invité à ce premier colloque, à la première rencontre des écrivains sur le thème «la Poésie et nous» et c'est à ce moment-là également que j'ai écrit les Poèmes de l'Amérique étrangère, en 1956. C'est par le biais nécessairement de la poésie qu'à cette époque-là de l'histoire du Québec peut se faire l'inscription d'un étranger marginalisé comme moi.

V. \& I.(2) - Vous avez dit auparavant écriture de l'exil? La poésie est-elle aussi mise à l'écart?

M. v. Schendel - Elle est mise à l'écart, elle est tenue en marge, mais par une sorte de marginalité qui est très dynamique pour elle puisqu'en fait la poésie va être un laboratoire de formes. De ce point de vue-là, je serais encore d'accord avec ce premier texte publié - c'est ce que je disais dans mon intervention de «la Poésie et nous». Au cours des années 1960 et 1970, déjà nous luttions contre la poésie comme genre, la fermeture dans le genre. Si je trouve quand même intéressante l'écriture de Hubert Aquin c'est parce qu'elle casse le roman et l'oriente vers la poiésis. Ma poésie a été reconnue un certain moment mais au fond sous de faux prétextes. Elle a été reconnue dans les années $60 \mathrm{au}$ moment de la redécouverte du nationalisme et on l'a fait s'identifier à ces expressions nationalistes. On a eu même l'amabilité de dire d'elle qu'elle avait été un précurseur, alors que c'est pas ça du tout. C'est ce qu'on a appelé la poésie du pays mais c'est une appellation que je crois malheureusement avoir été le premier à lancer dans une critique que j'avais fait paraître au Nouveau journal en 1961, j'y tenais la rubrique de poésie toutes les semaines. J'avais eu cette expression, qui était malheureuse, elle a été ensuite reprise par quelqu'un à Ottawa, et elle a fait fortune. Malheureusement : car c'est aussi une des raisons pour lesquelles les jeunes poètes, les jeunes écrivains rejettent en bloc sous cette appellation totalitaire toute une période extrêmement passionnante des lettres québécoises... encore la plus passionnante.

V. \& I.(2) - Vous seriez d'accord avec T. S. Elliot qui disait que la poésie ne peut être que nationale, non pas nationaliste. Ça, c'est ce que Gaston Miron s'est tué à essayer de faire comprendre et en même temps avec toutes ses contradictions.

M. v. Schendel - Oui, on se suivait beaucoup à l'époque. C'est Gaston Miron d'ailleurs qui m'avait fait découvrir ce texte de T. S Elliot. On suivait beaucoup lui et moi ces orientations de l'art, de la même façon que plus tard d'ailleurs, j'extrapole, sur le terrain de l'écriture politique, plus explicitement politique j'ai dirigé la revue Socialisme québécois, je me suis acharné à toujours distinguer nationalisme et question nationale, à prendre position pour la question nationale mais à me battre contre le nationalisme. 


\section{Poèmes de l'Amérique étrangère}

V. \& I.(1) - Et quand tu publies Poèmes de l'Amérique étrangère tu y vas assez carrément, tu dis: Amérique, Amérique, terre carnivore... Je ne te possède pas, Je m'exaspère je ne te crains pas, Je me surmène et je te veux, Malgré moi contre moi contre mon sang, Contre mes sens d'homme aiguisé, Contre ma rage de tourbe et le sel de mon sang qui/ coule des marais de mes Flandres... Il y a cette conjonction constante du pays, des deux autres pays et du troisième et d'une volonté de conquête amoureuse...

\section{M. v. Schendel - Amoureuse mais rageuse en même temps.}

V. \& I.(1) - Tes lecteurs sont habituellement portés à privilégier les premiers ensembles de ce recueil à cause de ce que tu dis de l'Amérique comme tel et de l'attaque, de l'apostrophe...

M. v. Schendel - Je dirais malheureusement et, en même temps, disons que c'est un effet d'appareil. C'est-à-dire que ça rentre plus facilement. C'est facile d'apostropher l'Amérique, c'est l'effet d'Amérique d'autant plus qu'à ce moment-là l'Amérique est d'un poids extraordinaire et en même temps c'est une mythologie. Alors un recueil, c'est le premier qui porte en titre Poèmes de l'Amérique étrangère. Forcément ça a du succès et ça a beaucoup plus de succès que les autres qui à mon sens sont bien supérieurs.

V. \& I. (1) - La métaphore du pays est là très installée et tu participes pleinement à l'exploitation thématique du pays. Est-ce que tu participes ou non à l'édification de cette thématique?

M. v. Schendel - Je dirais que je l'ai critiquée cette thématique pour ce qu'elle me paraissait trop vague, pour ce que «le pays" étant nommé seulement sous ce vocable inorienté (et là je pense à un petit recueil de Jean-Guy Pilon, la Mouette et le large) on peut en dire n'importe quoi et ça autorise n'importe quelle poésie facile et c'est pourquoi je n'acceptais pas du tout ça. J'ai été très étonné d'un commentaire paru dans Spirale l'an dernier après la publication de Autres. Autrement sous la signature de Hugues Corriveau. Étonné de le voir relever, je crois que c'était de l'inculture de sa part, un non-savoir lire, de relever la mention selon laquelle prétendument je serais encore un de ces poètes du pays, caractéristique de cette génération. Ça m'a beaucoup étonné parce que je ne peux pas accepter ça, je ne peux pas accepter de parler du «pays»: qu'est-ce que c'est le pays, c'est rien, c'est un no-man's land, c'est rien du tout, c'est un pays et encore! Pour que ce soit un espace et un espace qui puisse être verbalisé, transformé, il faut que ce soit un certain lieu d'action dans ce pays particulier. Un espace national, ce n'est pas le pays. Un espace national c'est un espace de lutte, c'est un espace social. Vraiment je trouve qu'il y a une inculture de la part de ce Hugues Corriveau, il y a un grand effet de paresse, un aplatissement complet. Donc il n'a pas su lire ce qu'aucun autre poète n'a dit et n'a pu dire - non pas su dire mais pu dire ce que moi j'ai dit, probablement parce qu'il y avait une autre forme de l'histoire intervenant dans l'écriture et qui faisait l'écriture. Et pour moi cette histoire n'était pas un mythe, elle pouvait le devenir par le poème mais ça 
c'est tout à fait différent, l'histoire en tant que telle n'était pas un mythe. Elle n'était pas le genre d'histoire qu'on a appris aux enfants des élites québécoises pendant des générations sur leur propre image et qui était elle, proprement, du mythologique.

V. \& I. (1) - J'ai trouvé généralement que dans ce premier recueil tu te donnes, tu recherches vraiment le pays comme une maîtresse ou comme une femme vraiment à conquérir mais en même temps tu te donnes comme poète. Enfin celui qui s'énonce ici, celui qui assume la position du narrateur veut se donner une capacité d'intervention constante, une capacité de transformation...

M. v. Schendel - Je crois que c'est beaucoup plus ça d'ailleurs. Pour ce qui est de la métaphore érotique, c'est vraiment une métaphore, finalement en ce sens assez rhétorique.

Y. \& I. (1) - Et tu te programmes. Après avoir défini le milieu québécois dans le poème "Au temps qu'il fait au temps qu'il ferait", quand tu dis: Peuple obsédé, Peuple sans air, Peuple acculé aux fractures de ses rêves, Peuple amoureux des censures de sa chair, Peuple de nuits lourdes, Paroles perdues dans les puits de sa brume... Ces paroles sont dures et généralement il y a des échos de ce genre de paroles qui continuent, mais très fréquemment, tu veux intervenir ou en tout cas le narrateur veut intervenir et dans Noms de désastre il y a une programmation réelle de l'action à mener: Avance à la rescousse du vieux Monde, Avance et hurle d'un plus haut tremblement que la poussière de sirène... J'aimerais que tu dises si le narrateur ici renvoie aux préoccupations du poète. Est-ce que l'on est vraiment tout à coup renvoyé dans la société de référence et au sort et au statut du poète que tu étais? Est-ce que j'ai raison de faire une lecture au premier degré d'une programmation d'actions, d'interventions en cette "Amérique étrangère" de la part de Michel van Schendel?

M. v. Schendel - Je crois que tu as raison, ce doit être ça. Je ne sais trop comment répondre parce que ça c'est un texte très ancien, je n'écris plus du tout comme ça. Quelles que soient les plages de mes interventions, c'est vrai que ça a toujours été des interventions, toujours, et ça continue d'en être, des modes d'action sociale - en enlevant, en expurgeant, toute catholicité du terme action sociale: il faudrait trouver un autre terme - de pratiques, de modes d'interventions sociales. Mais d'un autre côté, il m'est malaisé aujourd'hui d'en parler même si cependant ces textes-là ont été repris dans l'édition 1981 où ils apparaissent avec des textes plus récents. Il m'est difficile de rappeler les circonstances dans lesquelles tout ça était produit; j'en ai parlé, évoqué quelques-unes tout à l'heure. Quoi qu'il en soit de ces circonstances, elles sont prises dans une histoire qui par conséquent n'est pas seulement une histoire locale. À travers tout ça, bien sûr, c'est moi qui interviens, et le narrateur c'est aussi le poète en l'occurrence. Ça je ne le cache pas, je n'ai pas à le cacher. Et c'est ce qui fait l'acte d'écriture, cet acte-là d'écriture. C'est la première fois, vraiment, qu'on m'interroge là-dessus... C'est en même temps un appel - et en ce sens c'est un programme sans doute - à une 
transformation par l'écriture dans la mesure ... ou est-ce là de façon vraiment autonome? Mais c'est tout de même un appel à une transformation sociale. Mais une transformation sociale sans frontière. C'est-à-dire où mon expérience particulière d'homme qui est un poète intervient légitimement pour, pas pour - il n'y a aucune espèce de finalisme - de façon que, si l'écriture est vraiment réalisée, et je doute qu'elle le soit vraiment là - elle l'est plus tard je crois - le lecteur à qui je m'adresse, sinon je ne publierais pas, puisse lui-même, lui aussi à partir de sa propre expérience, faire ce même cheminement ou un autre cheminement mais en tout cas convergent ou parallèle ou de même mouvement et abandonne les enfermements de ces mythologies nationales particulières québécoises.

V. \& I.(2) - J'ai l'impression qu'avec ce recueil vous donnez au Québec, au pays vague, une dimension américaine et ça me paraît très important...

M. v. Schendel - Et donc il cesse d'être vague. Mais c'est pas américain dans le sens étatsunien. C'est trans-américain.

V. \& I.(2) - Exactement, c'est le continent.

M. v. Schendel - Et c'est la part d'américanité, donc de quelque chose qui n'a pas été dit parce qu'il y a eu trop de frilosité pour le dire.

\section{V. \& I.(2) - Sauf Gaston Miron?}

M. v. Schendel - Sauf Gaston Miron et sauf Paul-Marie Lapointe.

\section{V. \& I.(2) - Je pense à Compagnons des Amériques...}

M. v. Schendel - Compagnons des Amériques et aussi un peu plus tard, en 1963, à I.B.M. de Paul-Marie Lapointe qui est un très grand poète. Bon, je crois qu'il y a tout ça. Et nous étions quelques-uns à percevoir ces choses-là. À les percevoir poétiquement, et peut-être encore un petit peu trop enfermées dans le cas de Miron et Lapointe. Chez moi c'est beaucoup plus articulé sur les autres scènes de ma pratique. Parce que je ne suis pas seulement un poète. La poésie n'a jamais été pour moi une île, un refuge. Elle était, elle est la forme radicale de la distance nécessaire, sinon rien n'est visible, compréhensible avant longtemps. Elle l'est devenue encore beaucoup plus, et de façon très articulée par la suite - mais elle l'était déjà à ce moment-là. Une distance? Oui. La poésie est le lieu d'une vérification des autres discours, de leur vérité pragmatique, donc de leur vérité théorique mais toujours conjoncturelle. L'écriture poétique est ce lieu-là. C'est pourquoi j'ai à la fois besoin de plusieurs scènes, celle de l'enseignement, celle de l'action politique - mais ça, ça dépend des circonstances, c'est pas toujours possible (actuellement, et depuis plusieurs années, c'est radicalement impossible pour moi) : c'est le rêve d'un intellectuel organisateur qui se poursuit et qui s'accomplit dans l'écriture poétique. En ce sens, tu as peut-être raison de voir qu'il y a un aspect programmatique. Je ne suis pas sûr cependant que l'aspect programmatique, ainsi énoncé dans le discours poétique de la poésie, soit le mieux venu. 
V. \& I. (1) - Mais on peut aussi voir l'inverse. Quand tu tiens un discours amoureux, de la même manière que tout à l'heure tu insérais un dispositif amoureux dans un discours poétique qui était politisé, quand tu tiens un discours amoureux, tu introduis des images, des métaphores politiques. Regarde Mot à gouttes, qui déforme le "goutte à goutte", tu dis: Mon bel amour, ce qui évoque pour moi bien sûr un peu Gaston Miron, Mon bel amour navigateur; tu dis Mon bel amour la vie si nue mon avril et ma brume, Les creux de ma pluie, dans les poings marcheurs de/ caresses... Là je me dis: c'est très beau, mais en même temps il y a une façon de parler d'amour qui s'incarne dans des images de revendications politiques: Les poings marcheurs de caresses...!?

M.v. Schendel - Et en même temps ça provoque une certaine contradiction dans le poème et c'est pourquoi ça devient poétique à ce moment-là parce que la tension est explicite, elle est organisée, c'est elle qui organise le poème.

V. \& I. (2) - Ce n'est pas uniquement politique peut-être si l'on accepte justement qu'il y ait cette tension si nécessaire entre sexes.

M. v. Schendel - Oui mais c'est aussi... Celui qui écrit ça n'est que Michel van Schendel, ce n'est pas un autre, mais c'est aussi, il me semble que l'on pourrait le dire au plan biographique dont on a parlé tout à l'heure, c'est aussi celui qui a constaté des tensions entre le régime de l'amour, ou les régimes de l'amour et les régimes de l'action politique. Ça va de pair mais ça ne va pas sans de très fortes tensions et sans d'immenses décalages qui peuvent être destructeurs d'ailleurs. Une façon de ne pas être détruit par ça, c'est d'écrire.

\section{Militer}

V. \& I.(1) - Et alors là, si on privilégie maintenant ton activité militante, en décembre 58 tu participes activement à la grève des réalisateurs de RadioCanada. Quel sens ça avait pour toi, à ce moment-là ?

M. v. Schendel - J'étais pas un premier rôle, j'étais même pas un second rôle, j'étais un marcheur de la grève.

\section{V. \& I.(1) - Tu n'étais pas syndiqué?}

M. v. Schendel - Si. J'étais membre de la Société des auteurs dramatiques et j'étais scripteur à Radio-Canada. Les réalisateurs qui venaient de former leur syndicat étaient en grève et par solidarité avec eux nous avons décidé de les appuyer dans la grève. Quand je dis nous, c'est la majorité des auteurs dramatiques. En même temps, je crois qu'il y a autre chose, pour moi comme pour d'autres, à cette époque. Il faut pas oublier que ce qui se passe à Radio-Canada à la fin des années 50 est très important pour l'ensemble de l'intellectualité québécoise qui d'ailleurs accède à d'autres fonctions, c'est-àdire à des fonctions plus salariales; son statut social et idéologique, disons de légitimité, commence à se modifier assez sensiblement et ce qui se passe à 
Radio-Canada, qui a été jusque-là le seul lieu (contrairement à ce que c'est aujourd'hui: c'est le dernier lieu) le seul lieu à ce moment-là où il y avait la possibilité d'une discussion, relative bien sûr, mais tout de même d'une discussion, un lieu où il y avait tendance en tout cas à reculer les frontières des tabous. Des tabous religieux, des tabous dogmatiques. Des tabous. Ce qui se passe à Radio-Canada est très important. Et par conséquent, je crois que ce n'est pas simplement une question de solidarité, c'est aussi une question de prise en charge par tous ceux qui appuient cette grève de leur propre sort. C'est aussi dans le contexte approprié, dans les conditions politiques de la fin $\mathrm{du}$ duplessisme. C'est à ce moment-là que ça se passe. C'est la fin d'un certain régime libéral au gouvernement fédéral. C'est beaucoup de choses de cet ordre. Ce qui se passe à Radio-Canada est également annonciateur, donc, de ce qui va être le plus systématiquement organisé, non sans ambiguité, par la révolution tranquille au Québec au début des années 60 . C'est aussi pour ce qui me concerne, moi et quelques autres, un moment où au plan de l'organisation politique on a essayé de faire avancer des choses. Une toute petite minorité, on avait fondé le P. S.D., le Parti Social Démocratique. C'est à la même époque. C'est après le rapport du vingtième congrès du P. C.U.S. (le Parti communiste de l'Union Soviétique), après en 56, après les interventions soviétiques en Hongrie et en Pologne, à l'automne 56 qui se sont traduites également par l'éclatement de ce qui restait du Parti Ouvrier Progressiste au Québec; j'avais tenu cela le plus possible à distance pour des raisons de sécurité et aussi parce que je ne comprenais pas très bien la fermeture de ces communistes-là, leur inintelligence politique, bien qu'ils aient eu beaucoup de courage à maintenir cette inintelligence politique, si je puis le dire de cette façon-là. Mais ce qui reste de ce Parti va à la débandade. Il ne résiste pas aux révélations du rapport Khrouchtchev. La majorité des gens s'en vont. Il y a également des gens qui n'ont jamais été membres du Parti communiste ou du Parti ouvrier progressiste, mais qui sont des syndicalistes de vieille souche, des syndicalistes de la gauche du mouvement syndical, comme Jacques-Victor Morin, comme Michel Chartrand, comme d'autres, à l'époque aussi Fernand Daoust de la F.T.Q., essaient de lancer, d'organiser une question: pourquoi la société québécoise ne pourrait accueillir un mouvement socialiste voire un Parti socialiste? Et on se retrouve périodiquement pour essayer d'organiser ça. Ça va faire long feu et finalement ça va se traduire par l'absorbtion dans le Nouveau Parti Démocratique qui sera créé au début des années 60 . Mais donc, pour revenir à toute cette période, la participation à la grève de Radio-Canada doit être située-dans cet éclairage à la fois politique, d'ensemble, et particulier pour ce qui me concerne.

V. \& I. (1) - Quelle est ta position personnelle après 56, après l'histoire hongroise? Est-ce que tu restes un communiste aussi fervent qu'avant ton arrivée à Montréal ? Comment te situer après le rapport Khrouchtchev?

M. v. Schendel - C'est une façon de reprendre la question qui avait été posée ce matin et à laquelle je n'avais pas répondu. Peut-être que maintenant on peut commencer à y répondre. De toute façon c'est une question inévitable étant donné que par exemple, beaucoup plus tard encore, un type comme 
Claude Gauvreau m'a accusé d'être un stalinien. On ne peut pas faire l'économie d'une réponse. Encore beaucoup de gens continuent à croire que je suis un stalinien. Je voudrais un peu revenir en arrière. Bien sûr quand j'étais jeune membre du parti communiste français, jeune responsable étudiant ou cadre intermédiaire du parti communiste français dans le secteur étudiant, dans cette époque de guerre froide, dans cette conjoncture extrêmement violente - t'étais blanc ou t'étais noir - il était impensable je crois bien, non pas impensable pour les autres qui n'étaient pas communistes, mais si on essayait de viser à des transformations effectives, je crois qu'il n'y avait pas d'autres moyens que d'être communiste, d'y adhérer avec toute son efficacité possible, et ça veut dire aussi qu'il n'y avait pas moyen d'échapper au stalinisme. On était stalinien et on l'était sans même bien savoir ce que c'était. On se faisait traiter de «stalinien» mais ça c'était une insulte. C'était reçu comme une insulte et la seule réponse qui se pratiquait était de revendiquer ce titre. Donc nous étions, oui bien sûr, des marxistes-léninistes-staliniens. Et alors, par rapport à ça, j'ai pris évidemment toutes mes distances à partir du moment où j'ai su ce que, auparavant, je refusais de croire, mais là il n'y avait pas moyen de ne pas y croire. Et il fallait réfléchir au contraire à toutes les conséquences et à toute la signification au plan de l'édification de ce type assez particulier finalement, et non pas universel, de socialisme, celui qui s'était édifié en U.R.S.S., qui, je crois bien, continuait de s'édifier mais était beaucoup plus contradictoire et beaucoup plus négatif en même temps, à travers ses effets positifs, beaucoup plus négatif que ce qu'on avait voulu croire. Ceci dit, quand j'étais étudiant, l'accent que nous mettions, nous, en particulier à la cité universitaire sur la construction du mouvement de la paix, impliquait une prise en considération de ce qui se passait du côté anti-communiste. La liaison n'était pas évidente, ce n'était pas simple du tout, et aussi demandait un autre type de stratégie que celle purement mécaniste-économiste qui continuait d'être pratiquée par l'ensemble des appareils communistes dirigeants et intermédiaires. La position dominante des appareils communistes était au fond la suivante: «le mouvement de la paix, oui; il faut mettre ça en accord avec nos revendications, nos revendications de travailleurs, etc. ", donc sur la scène économique. Et par rapport à ça, nous étions amenés à lutter. Nous nous sommes battus en particulier contre des gens de l'appareil tels que: Annie Besse, à l'époque c'était une dure stalinienne. Depuis sa séparation, Annie Besse a repris son nom de Kriegel, elle est devenue une des grandes spécialistes des problèmes soviétiques et du communisme européen, une anti-communiste acharnée aujourd'hui. Elle, c'était une stalinienne. Nous, nous l'étions et en même temps, dans la pratique de notre travail d'organisation, nous étions en porte à faux par rapport à des staliniens de pure obédience. Voilà la réponse que je ferais mais évidemment après 56 des gens comme moi ont vécu de façon absolument déchirante. Quelle gifle nous recevions... Il fallait être très fort pour ne pas céder à un désespoir absolu et ne pas tourner le dos à toute l'histoire, telle que nous l'avions interprétée.

V. \& I.(1) - Alors, à quoi tu t'accrochais à ce moment-là? Ả quelle sorte de socialisme? 
M. v. Schendel - Je suis devenu forcément de plus en plus marxiste.

V. \& I.(1) - Qu'est-ce que ça veut dire alors?

M. v. Schendel - Un marxiste de plus en plus critique.

V. \& I.(1) - Un marxiste de Marx...

M. v. Schendel - Oui, et pas seulement, Lénine aussi. J'ai relu à partir de ce moment-là, surtout dans les années 60 , les textes de Lénine, les textes de Gramsci. Alors là, j'ai redécouvert... j'ai trouvé une vision politique de l'organisation révolutionnaire beaucoup plus fine, beaucoup plus intelligente que je ne découvrais en relisant Staline.

V. \& I.(1) - Est-ce qu'encore aujourd'hui, tu te définis comme marxiste?

M. v. Schendel - Le marxisme a toujours été tendanciel chez moi. En ce sens, oui, je me définis encore comme marxiste. Je ne peux pas dire que je sois un militant: en ce sens, je ne suis pas un marxiste. Dans la mesure où cependant je l'ai été sur différentes scènes, j'ai toujours essayé d'apprendre la leçon de cette histoire des textes de Marx et d'autres, jusqu'à Gramsci; Lénine, un temps, j’ai beaucoup laissé tomber, beaucoup laissé de côté.

\section{V. \& I.(1) - Et Engels?}

M. v. Schendel - Engels moins, sauf pour les quelques aperçus qu'il y a chez Engels dans sa correspondance avec Mehring sur la force de l'idéologie, mais malheureusement tout cet aspect des choses, c'est-à-dire ce que c'est que l'idéologie, quelles sont les formes de l'idéologie, quelle est l'efficàcité de l'idéologie, tout cet aspect des choses avait été, dans les faits, laissé largement de côté par la tradition, par la vulgate marxiste si l'on veut parler ainsi, au point que, quand on parlait de la lutte idéologique, c'était la lutte au profit de l'expansion des idées, des idées marxistes ou léninistes: c'était vraiment une conception extrêmement pauvre, rudimentaire de ce que c'est que l'idéologie. Par rapport à ça, évidemment j'ai été obligé à la fois de m'inspirer, de revenir aux textes, d'essayer de les lire plus intelligemment, plus finement, de suivre en ce sens les exemples qui étaient proposés et en même temps de prendre mes distances parce que, encore aujourd 'hui, c'est sur cette base qu'on peut peut-être découvrir une théorie de l'idéologie mais cette théorie, elle doit être faite et on est encore très en retard. Les derniers grands travaux sont aujourd'hui datés, ceux d'Althusser. On n'a pas fait de grands progrès. Dans la mesure où on travaille sur cette scène-là au plan théorique et donc aussi au plan de l'écriture, c'est l'écriture qui forme, qui informe, qui investit cette scène de l'idéologie; dans cette mesure-là, on est obligé de prendre des distances. On est obligé d'inventer.

V. \& I.(1) - Pour toi, le marxisme est donc une perspective d'invention? davantage qu'une perspective doctrinaire... C'est une fonction critique. 
M. v. Schendel - Oui, c'est une fonction critique et c'est donc une fonction d'invention.

V. \& I. (1) - Et la fondation de Liberté? Est-ce que pour toi ça a eu une importance, du fait que tu te retrouves en compagnie de Belleau, Carle, Godbout, Hénault, Lapointe, Ouellette, Pilon? C'est une affaire d'amitié ou est-ce que, au départ, il n'y avait pas une ambition socio-politique assez rapidement disparue (puisque tu n'y es pas resté, pas davantage Gilles Hénault) au profit d'une spécialisation qui serait littéraire, culturelle? Est-ce que dans ta participation à la fondation, il y avait toute cette dimension globale, politico-culturelle?

M. v. Schendel - Oui. Bon alors, amitiés, disais-tu non. En fait, le seul alignement de tous ces noms montre assez, je crois, qu'à l'époque il y avait. une forme de compromis qui était réalisée et qui pouvait, me semble-t-il, être pratiquée par les uns comme par les autres. Des gens comme Hénault, PaulMarie Lapointe à l'époque et moi n'avions pas grand-chose en commun au plan de l'amont politique avec des gens comme Belleau, Godbout ou Filiatrault et Pilon. Les rapports étaient amicaux mais nous avions de tout autres préoccupations. Ceci dit, quelles étaient nos préoccupations? En tant que premier secrétaire de rédaction de la revue, j'avais été chargé de préparer, avant évidemment les débuts officiels, une politique, l'énoncé d'une politique de revue. J'avais mis l'accent effectivement sur les aspects les plus larges d'une politique culturelle, pour sortir de la gangue étroite du littéraire, pour essayer de voir quels étaient les rapports entre le littéraire et d'autres formes d'expression d'une part, et là-dessus, je crois qu'il n'y avait pas de problèmes. Mais aussi : quels étaient les aspects organisationnels à découvrir et quel était le rapport avec le changement social, avec les transformations sociales qui s'opéraient sous nos yeux. Est-ce que nous allions, nous en tant que littéraires ou jeunes intellectuels, rester distants, éloignés de ça au nom de la revendication abstraite de la liberté d'expression? Et c'est ce programme qui avait été débattu assez longuement. Finalement, il y avait eu une espèce de fin de non-recevoir. Ce programme n'avait pas été adopté comme politique de la revue. Néanmoins, on s'était dit à ce moment-là, si je me souviens bien, qu'on pouvait rester, Gilles Hénault, moi et quelques autres. On pouvait rester dans la revue; peut-être, la revue une fois en place, on pourrait agir de l'intérieur. Hénault et Lapointe se faisaient moins d'illusions que moi sans doute. Il y a eu la grève de Radio-Canada, là il y a eu un premier éclatement au sein de l'équipe pour des raisons pas trop graves. Pilon, à l'époque, était un cadre de Radio-Canada, pour lui c'était difficile; néanmoins nous avons tout de même publié un petit manifeste au sujet de la grève de Radio-Canada dans le premier numéro et par la suite je ne sais plus exactement ce qu'il y a eu après la grève. Il y avait aussi l'autre moitié de l'équipe... Il y avait certainement des rapports d'amitié, pas seulement d'amitié mais au fond, disons, des horizons idéologiques communs entre Pilon, Belleau ou Godbout et les autres. Il y a eu, juste après la publication du premier numéro, une discussion extrêmement orageuse, Pilon était prêt à remettre sa démission, il y avait là vraiment un rapport, ce n'était pas un rapport à conflits de personnalités 
entre lui et moi, pas du tout: c'était vraiment un rapport très conflictuel entre deux orientations, l'orientation "boîte aux lettres", c'est ce que je craignais que la revue ne devienne, et l'orientation que j'avais proposée. Conflit d'autant plus orageux que l'orientation que j'avais proposée n'avait jamais été discutée sur le fond, on n'en avait jamais décidé, on n'était jamais passé aux décisions par rapport à ça, ou plus exactement on n'avait jamais pris en considération dans les décisions prises les orientations que je proposais.

V. \& I.(1) - Et pour toi, dans les orientations que tu proposais, le politique chapeautait le culturel et non l'inverse?

M. v. Schendel - Oui mais c'était un politique pas nécessairement militant, un politique large. Au fond, j'ai encore ce document dans des caisses quelque part, je crois bien que c'était relativement innocent, mais pour l'époque ce ne l'était pas. Alors donc on s'est séparé à ce moment-là, Pilon a offert sa démission. J'ai répondu; Allez-y, continuez, c'est nous qui partons.

V. \& I.(1) - En quelle année, le départ?

M. v. Schendel - Dès le deuxième numéro, paru en mars-avril 1959.

V. \& I. (1) - Alors, est-ce qu'on peut n'être pas très étonné que tu passes ensuite à Cité libre? Parce que tu n'as pas d'autre lieu de manifestation «politique»?

M. v. Schendel - Non.

V. \& I.(1) - Tu vas aussi être chroniqueur pour la série télévisée d'Hubert Aquin, Arts et lettres et tu fondes la section québécoise du N.P. D. en $1960 \ldots$

M. v. Schendel - Je suis l'un des membres fondateurs.

V. \& I.(1) - Tu diriges les Editions de l'Hexagone ... ce qui n'est pas banal en soi, bien sûr, tout cela mériterait beaucoup de questions. Mais on peut s'interroger tout de suite sur le fait que tout à coup tu accèdes, pour ainsi dire, au "nec-plus-ultra». Cité libre, c'est quand même un refus très "reçu» à l'époque. Ce n'est pas forcément ce qu'il y a de plus révolutionnaire, c'est dans la lignée de la Relève, c'est personnaliste.

M. v. Schendel - Une chose dont j'ai toujours été très éloigné.

V. \& I.(1) - Pour faire le topo très rapidement, pourquoi vas-tu à Cité libre? C'est Trudeau et Pelletier qui t'y invitent?

M. v. Schendel - Oui, en même temps qu'Adèle d'ailleurs.

V. \& I.(1) - C'était peut-être le seul lieu intéressant de manifestation antiduplessiste, de protestation?

M. v. Schendel - Mais à un moment... Bon, c'était d'habiles flaireurs de vent, si je peux dire. Ils sentaient le vent tourner et savaient très bien, ils 
étaient bien placés pour le savoir, que le duplessisme en était à sa fin et qu'il allait y avoir un virage. L'intéressant ce n'est pas que je me retrouve là, l'intéressant c'est que des gens comme moi et d'autres, je ne suis pas le seul, il y a Pierre Vallières aussi qui se trouve là à ce moment-là et d'autres, c'est-àdire bien à gauche par rapport aux orientations habituelles de Cité libre, n'aient pas été demandés plus tôt. Je crois pouvoir le dire, je n'étais pas une cible personnelle, enfin ce n'est pas par rapport à Cité libre que j'ai subi un certain ostracisme au cours des années cinquante. Il y avait eu, c'est vrai, des problèmes avec Gérard Pelletier qui avait fait savoir à qui de droit que j'étais un jeune homme brillant, intelligent mais communiste. (Il m'a dit plus tard: Je voulais te protéger). C'était très grave dans les années cinquante de dire ça. Mais par rapport à Cité libre, je n'ai pas subi d'ostracisme particulier ou plutôt j'étais dans le lot de tous ceux qui étaient tenus à l'écart. Comment se fait-il que dans les années 1950 l'équipe de Cité libre reste enfermée sur elle, dans ce personnalisme extrêmement étroit, anti-clérical mais très, très catholique, donc: une espèce de para-cléricalisme et où politiquement, au plan de la politique éditoriale, on fait la même chasse, pratique les mêmes exclusions à l'endroit de tout ce qui est à sa gauche; voir par exemple le sort fait par eux à une revue qui était intéressante, Place publique, au début des années 1950 . Ils étaient aussi duplessistes vis-à-vis de leur gauche que Duplessis l'était, publiquement, vis-à-vis d'eux.

V. \& I.(1) - Il y a une chose fascinante pour cette époque-là, c'est que tout à coup tu t'affirmes vraiment comme journaliste. Ça semble important puisque tu es à temps complet au Nouveau journal et puis ensuite, de 1962 à 1965, à temps complet à La Presse donc très occupé, analyste et reporter aux nouvelles économiques et puis titulaire de trois prix de journalisme. Tu es vraiment dans une carrière de journaliste.

M. v. Schendel - Maintenant, je crois que ce sont les circonstances politiques et que...

V. \& I. (1) - Et puis qu'arrive-t-il? Pourquoi es-tu tout à coup orienté du côté de l'enseignement, assez rapidement, à compter du milieu des années soixante, de telle manière qu'à compter de 1966 on est porté à dire: là, c'est une nouvelle vie qui commence, c'est le côté pédagogue, enseignant qui gagne sur tous les autres.

M. v. Schendel - Je dirais que j'ai dû, tout au long de ma vie professionnelle, cultiver plusieurs fers, fers et «faires", c'est la même chose. Précisément parce que les circonstances pour moi, les conditions faites n'étaient pas faciles et il fallait toujours que je trouve les moyens d'échapper aux exclusions, donc de pouvoir vivre tout de même, de pouvoir avoir aussi une vie professionnelle, c’était pas facile ça. Par conséquent, dans les années 50 j'avais essayé d'être journaliste mais j'avais été refusé. J'avais été refusé justement pour des raisons politiques. À partir de 60 , les conditions changent. Il ne faut pas oublier que le Parti libéral de Lesage, et bien d'autres que Lesage, ne pouvait venir au pouvoir qu'en pratiquant une autre formule d'alliance que celle sur laquelle 
s'étaient appuyés le régime duplessiste et les anciens régimes libéraux au Québec, qui avaient toujours fait alliance avec l'aristocratie foncière et donc cléricale, l'église, la vieille, la grande propriété foncière; et la grande et petite banque d'affaires. Lesage, pour parvenir au pouvoir, a besoin de déblayer le terrain et pour déblayer le terrain, il faut des bulldozers; les bulldozers, c'est les intellectuels. Les intellectuels ne sont pas duplessistes, les intellectuels ne sont pas non plus libéraux ou quand ils le sont, ils le sont de gauche. Ces intellectuels-là voient très bien que c'est pour des raisons tactiques qu'ils vont devenir libéraux. C'est, d'ailleurs, ce qui se fait, c'est ce qui se pratique à ce moment-là. C'est cette alliance. Et donc il y a une ouverture, et donc on a besoin de journalistes, et donc on a besoin d'un journalisme critique. C'est, je crois, ce qui explique le succès du journalisme des années soixante, tant par la fondation du Nouveau journal que par la réforme du journal La Presse qui est devenu à ce moment-là, pendant quelques brèves années mais tout de même pendant cinq, six ans, un journal intéressant.

V. \& I.(1) - Tout à fait. Et tu te trouves là comme par hasard? Là où ça se joue?

M. v. Schendel - Et bien oui, je me trouve là comme par hasard parce que j'étais prêt pour ça, tout comme j'étais prêt pour l'enseignement. Et à partir du moment où il y a eu vraiment un coup de matraque sur la profession de journaliste, à la fin de la révolution tranquille...

\section{V. \& I.(1) - En 1966.}

M. v. Schendel - Même avant, ça a commencé de se décider en 1964 à l'occasion de la grande grève deLa Presse, la grève qui avait duré sept mois, c'était ça qui était en question. C'était les formes et les limites de la liberté de presse, de la liberté d'analyse, de l'intervention critique des journalistes. Le régime Lesage, et les autres gouvernements par la suite encore plus, trouvait que vraiment on était allé trop loin. Il fallait donc arrêter ça, couper les frais. On a donc réglé la grève à l'avantage matériel des journalistes mais la liberté de presse c'était fini. À ce moment-là, il y a eu toutes sortes de décisions prises à La Presse.J'étais journaliste à La Presse à ce moment-là,on a congédié Gérard Pelletier avec lequel je n'étais absolument pas en accord. Mais congédiant Gérard Pelletier, on essayait d'atteindre les journalistes. Les journalistes n'ont pas réagi. J'ai trouvé que c'était une erreur politique et que, comme de toute façon depuis la fin de la grève on me donnait de moins en moins de travail ou quand j'en prenais l'initiative, il était très difficile de faire passer mes papiers, j'ai donné ma démission. En donnant ma démission, je m'en suis expliqué d'ailleurs à l'époque dans un long texte que Le Devoir a publié en 1965 , je savais très bien que je prenais le risque de quitter le métier et c'est ce qui est arrivé. D'autant plus que, à ce moment-là, j'avais écrit dans Parti pris.

V. \& I.(1) - Justement. Alors, là, tu as déjà repéré un autre lieu de manifestation et comme par hasard c'est encore un lieu qui sera historiquement marqué, peut-être davantage que même la presse de cette époque parce que Parti pris jusqu'en 1968 sera le seul lieu intéressant, beaucoup plus que ne 
l'est encore pendant un certain temps Cité libre, je veux dire de manifestation, de contestation. Et alors là, que fais-tu dans ce lieu qui n'est pas réellement marxiste-léniniste, qui a une interprétation assez libre du socialisme...

M. v. Schendel - Très culturaliste.

V. \& I.(1) - Très culturaliste et à qui tu proposes une analyse de «la maladie infantile du Québec", donc une version très léniniste de la situation historique?

M. v. Schendel - C'est très critique mais en même temps, et ça c'était quelque chose que je trouvais enfin avec... que j'ai trouvé pendant peu de temps parce que j'ai dô faire autre chose... Mais j'ai trouvé un climat de discussion et de confiance parmi ces jeunes gens qui étaient beaucoup plus agités à Parti pris - toi, je ne te connaissais pas à l'époque, tu collaborais aussi - un climat que je n'avais pas trouvé par exemple dans mes tentatives de discussion avec mes collègues de Liberté ou, évidemment, que je n'avais pu trouver avec les gens de Cité libre et en général avec les intellectuels ou les intellectuels producteurs de Radio-Canada. Et ça, c'était intéressant. C'est-àdire que ce texte que je leur avais remis était le résultat de nos discussions et ils acceptaient la critique, même si cependant ça n'a pas eu d'effets pratiques. C'est passé comme une lettre à la poste et puis ils ont continué leur petit bout de chemin. Il faut dire aussi qu'à l'époque ils avaient leurs propres problèmes d'organisation et il y avait au moins deux factions, il y avait la tendance Jean-Marc Piotte orientée vers le mouvement populaire et puis il y avait la tendance plus proprement culturaliste, je dirais, Chamberland et Maheu.

V. \& I.(1) - Et toi tu étais plus naturellement porté vers la tendance JeanMarc Piotte?

M. v. Schendel - Oui et non.

V. \& I.(1) - As-tu participé ou non au lancement du mouvement populaire?

M. v. Schendel - Pas du tout. J'ai participé, mais indirectement, à certaines des retombées de ça lorsque, quelque temps plus tard, il y a eu une tentative de fusion entre le mouvement populaire de Piotte et de ses amis d'une part, et d'autre part le P.S.Q. Et je participais aux activités du P.S.Q., Parti Socialiste Québécois, qui avait été formé après les déconvenues nées de la formation du N.P. D. au fédéral.

\section{Variations sur la pierre}

V. \& I.(1) - C'est cette même année où tu publies deux choses importantes, pour la critique en tout cas, Variations sur la pierre et puis, ce qui n'a peut-être l'air de rien pour quelqu'un qui regarde rapidement dans le curriculum, c'est l'article sur "l'Amour dans la littérature canadienne-française". Moi j'en sais le rayonnement et il me paraît même à certains égards plus grand, en tout cas mieux reçu dans la critique que même Variations sur la pierre. 


\section{M. v. Schendel - Oui.}

V. \& I. (1) - Alors pourrais-tu nous parler d'abord de Variations sur la pierre? Quel est le projet de Variations sur la pierre? Est-ce que le titre coiffe ce que ça paraît être c'est-à-dire un ensemble non pas disparate mais en tout cas différencié?

M. v. Schendel - Je crois que le titre à ce point de vue-là peut, même s'il dit à posteriori de quoi il parle, définir lui-même les textes. Je crois qu'il y a une unité du texte, c'est un livre, c'est plus qu'un recueil. Des «Variations»: c'est au sens musical des variations sur un thème. C'est toujours, je crois, à ce moment-là, le même thème ou la même thématique de l'exil mais distanciée par rapport à l'espèce de prise de possession brutale que j'amorçais dans les Poèmes de l'Amérique étrangère. C'était parce que ça avait été une prise de possession assez brutale que ça avait eu un certain impact, malheureusement. Mais c'est aussi des variations, donc au sens musical du terme, mais sur un même matériau et la pierre c'est quelque chose de presque inamovible, c'est quelque chose de résistant, c'est quelque chose qui peut être difficilement friable, c'est quelque chose de dur, c'est un matériau dur qui résiste même aux inscriptions. Mais en même temps, s'il y a inscription possible là-dessus, il y a toutes les inscriptions possibles.

V. \& I. (1) - Est-ce que c'est par hasard qu'il y a, à la même époque, le recueil de Beaulieu qui allait devenir fonctionnaire ensuite?

M. v. Schendel - Maurice Beaulieu? Je connais deux titres Ã glaise fendre, c'est plus tôt, en 57 et Il fait clair de glaise, en 58 .

V. \& I.(1) - Il y a une sensibilité du minéral à cette époque que je lis chez Paul-Marie Lapointe, peut-être pas chez Gaston Miron, mais il y a quelque chose de cela. Est-ce que du côté de la matière?...

M. v. Schendel - Oui, il y a une découverte primitive, des caractères primitifs de la matière sur laquelle est inscrite, est inscriptive, quelque chose, une écriture. Il y a sûrement ça. Il y a, je dirais peut-être aussi, une sorte de réaction à une écriture de l'intervention un peu gauche. Il y a une réaction par laquelle est revendiquée l'autonomie même de l'écriture dans la mesure même où ce matériau fait résistance mais où, s'il se prête à l'exercice de l'écriture et donc si l'écriture accepte d'être elle aussi une résistance, il y a une autonomie par rapport à des modes brutaux d'intervention, d'affirmation. Au fond, c'est un livre qui est en réaction contre Poèmes de l'Amérique étrangère. J'avais quitté ça, il y a une sorte de possessivité dans Amérique étrangère qui commençait de me choquer.

V. \& I.(1) - Pourquoi ce statut particulier du poème «Au temps des Juifs» avec sa note explicative?

M. v. Schendel - Parce qu'à travers tout ça en même temps, si je signale ou revendique l'autonomie ou si je la formule, si je la forme, je suis encore 
mieux placé pour inscrire sur la pierre la matière même de l'histoire. Et c'est aussi mon histoire en tant qu'acteur.

V. \& I. (2) - Il y a une chose qui me gêne dans Veiller ne plus veiller par exemple, c'est la tendance à l'explication que... justement vous relevez à propos du poème "Au temps des Juifs». Cette note explicative par rapport à ce poème: là encore c'est la même chose, dans Variations sur la pierre, le premier recueil publié, il n'y en a pas et puis tout d'un coup, dans la rétrospective, on trouve la répétition.

M. v. Schendel - Ça peut être gênant, moi ça ne me gêne pas. Je crois que ça participe même de la variation. Il y a une polyvalence, une multiplicité des registres et je ne vois pas pourquoi il faudrait... Je crois beaucoup à l'écriture poétique mais je la crois active en tant qu'elle est multipliée. Je crois que cette multiplication vient aussi de la multiplicité des registres. Il peut donc y avoir des commentaires explicatifs ou simplement anecdotiques ou narratifs, ou simplement autres et c'est le rapport entre le poème proprement dit et cet autre registre qui introduit un poétique au deuxième degré. C'est ce rapport qui est blanc, ce rapport lui-même, il est silencieux. Vous avez à le construire ce rapport, il est là, il est manifeste, écrit, visible. Dans le cas de Veiller ne plus veiller, c'est autre chose. Quand j'ai repris pour l'édition de 80 le poème "Au temps des Juifs", il m'a semblé, suite à certaines remarques qui m'avaient été faites, et même certaines remarques très choquées, de gens qui avaient été très choqués par le fait que j'ai osé, dans le même poème, poursuivre la première partie consacrée «Au temps des Juifs" proprement dit, la poursuivre avec une deuxième partie où je parle du Québec, comme si c'était la même chose. Il m'a donc semblé qu'il y avait un rapport et je croyais que si ce rapport était assez explicite poétiquement, il avait aussi à être signalé d'une autre façon et en même temps c'était une façon pour moi de prendre mes distances par rapport à l'historique. Mais c'est une note entre parenthèses.

V. \& I.(1) - Tu t'es intéressé d'une autre manière au problème des Juifs. En 65 , tu publies une note sur le rôle de l'idéologie dans la poésie canadiennefrançaise dans les Juifs et la communauté française, est-ce que c'est une façon aussi de...

M. v. Schendel - Non, pas du tout. C'est tout à fait par hasard. Naïm Kattan s'occupait de ça et il m'avait proposé d'écrire un texte pour le premier numéro de ses Cahiers, pour le lancement et je lui avais proposé ça. Ça s'appelait Cahiers juifs mais en fait ça regroupait toutes sortes de textes, des études sur des sujets très divers.

\section{Écrire enseigner}

V. \& I. (1) - Là, nous voici arrivés à une frontière... à partir de 1966, c'est autre chose. Là, commence à s'incarner mieux que jamais ce double caractère de ta vie actuelle, celle de l'écrivain et de l'enseignant. Ce serait plutôt enseignant et écrivain, parce que tu es au département de français (et de linguistique) du Collège Sainte-Marie, puis à l'Université de Montréal... 
tout en collaborant à Lettres nouvelles et son numéro spécial «Écrivains du Canada", puis Gilles Marcotte te publie dans son Anthologie(Présence de la critique), tout s'oriente et en même temps il y a comme par hasard la revue Socialisme dont tu n'es pas fondateur mais...

M. v. Schendel - Non, je la reprends. Au moment où la première équipe est prête à tout laisser tomber, je dis que je veux continuer et ils me disent $O . K$.

V. \& I.(1) - Il semble de plus en plus évident que tu quittes le terrain de la "militance» au sens le plus strict, organisationnel de la base, pour travailler toujours au niveau de ces formes dont tu parlais tout à l'heure, mais davantage au niveau de la production écrite, de l'essai critique, de la réflexion. Ça n'empêchera pas la venue du syndicat et le militantisme syndical à l'UQAM où là tout se rejoint. Quand on entre dans cette époque-là, est-ce qu'il y a des faits qu'il est important de relever à tes yeux? Est-ce que par exemple le fait que tu ailles du côté de la revue Socialisme, c'est un repère?

\section{M. v. Schendel - Oui, très important.}

\section{V. \& I.(1) - Pourquoi la revue Socialisme?}

M. v. Schendel - Parce que c'était une revue beaucoup plus inquiétante que Parti pris et en même temps c'était une revue plus austère, donc beaucoup moins lue, sauf en 1971, nous avons publié alors un numéro qui était tout aussi austère que les précédents mais qui s'est vendu comme des "p'tits pains ", qui a été lu partout et qui continue encore d'être lu aujourd'hui, qui s'est vendu à trois mille exemplaires en un mois - c'était le numéro 21-22 sur «la Réaction tranquille» et les événements d'octobre. Je crois que ça a été très important depuis le début et surtout à partir du moment où j'ai assuré la transition en 1968 pour déboucher, deux ans plus tard, sur la fondation de Socialisme québécois. C'est la même revue mais qui continue avec un titre différent et où ceux qui restaient de la première équipe de Socialisme s'assemblent avec les dissidents de la revue Parti pris, Gilles Bourque, Gilles Dostaler, Jean-Marc Piotte et quelques autres. Ce qui était en jeu pour moi, c'était de contribuer aussi peu que ce soit au plan théorique et par la revendication de notre travail d'intellectuels en tant que tel - c'était difficile de se revendiquer comme intellectuel à l'époque - essayer de fournir les éléments de réflexion pour le développement à plus long terme d'une politique. C'était ça le projet et, de ce point de vue-là, je dirais que nous avons réussi. Même si là encore c'est très ingrat; nous avons réussi dans la mesure où, dans les années soixante-dix, le mouvement syndical a souvent repris certaines de nos réflexions, en se les appropriant purement et simplement et pourquoi pas, mais sans reconnaître tout ce qu'il devait à la qualité ou à l'originalité de cette réflexion et donc en se réservant, malheureusement, beaucoup de gauchisme par rapport à une réflexion qui, elle, n'était décidément pas nationaliste mais prenait fait et cause pour la revendication nationale.

V. \& I. (1) - Autre chose qui me frappe à ce moment-là c'est que, très rapidement, tu vas participer à l'évolution du Sainte-Marie puisque tu as un 
emploi au Collège Sainte-Marie tout en étant à l'Université de Montréal. Dès que l'UQAM est fondée, tu es de la fondation du département d'études littéraires (alors nommé «d'esthétique et de littérature»).

M. v. Schendel - Oui. Comment se fait-il qu'en 1965 j'abandonne, ou plutôt on abandonne pour moi ma fonction de journaliste, c'est le on, «je suis quitté de journalisme" si je peux employer cette affreuse formule mais il faut vraiment "passiver" ça et que je suis pris dans l'enseignement mais un enseignement, en même temps, pour lequel je suis prêt.

V. \& I.(1) - Mais tu reviens au fond à ta ressource première à ton arrivée ici?

M. v. Schendel - Exactement et que je n'ai jamais tout à fait quittée parce que, même quand j'étais journaliste, aux «Cours du Gésù", qui était à l'époque une forme d'éducation des adultes (organisée par les jésuites), on m'avait demandé de donner des cours du soir que j'avais assurés pendant deux ans, quand j'étais journaliste, au début des années soixante. Donc, je n'avais jamais vraiment quitté ça et encore une fois l'enseignement était comme le journalisme, comme la traduction, etc., c'était une des façons pour moi de me retrouver professionnel.

V. \& I.(1) - Mais après Radio-Canada, le journalisme, voici un autre secteur d'activité en plein développement historique, en plein essor et tu te trouves comme par hasard là?

M. v. Schendel - Oui, parce que j'étais prêt.

V. \& I. (1) - Quel sens cela a-t-il, à ce moment-là, quand l'UQAM est fondée? Est-ce que tu peux rappeler rapidement ce que ça représentait pour toi?

M. v. Schendel - Je pourrais dire d'abord qu'on est venu, en 1965 , me chercher à l'Université de Montréal pour la littérature québécoise et pourquoi? Parce qu'à l'époque, dans les universités, il ne s'enseignait pas de cours sur la littérature québécoise ou à propos de la littérature québécoise. Ceux qui essayaient ne pouvaient le faire que de façon très timide. Or, moi en tant que critique dans les années 50 et aussi en tant que journaliste, j'avais été l'un des premiers à explorer le champ de la littérature québécoise, donc c'est pour cette raison. Ils avaient besoin de quelqu'un là-dedans et ils étaient venus me chercher mais uniquement comme chargé de cours. Lës tentatives pour faire de moi un professeur régulier avaient échoué auprès de la haute administration puisque le secrétaire général de l'époque avait fait savoir au département qu'on n'aimait pas engager un journaliste.

\section{V. \& I.(1) - Au Sainte-Marie?}

M.v. Schendel - Non, à l'Université de Montréal. Au Sainte-Marie, c'était beaucoup plus libéral. Forcément, c'était jésuite. C'était très différent. C'est comme ça qu'au Sainte-Marie on est venu également me chercher en 1968, en 
même temps qu'Hubert Aquin et il y en avait d'autres. Mais tu essaies de savoir ce que ça représentait pour moi?

V. \& I.(1) - Oui et puisque Voix et images est publiée par l'UQAM - sans faire quelque sort privilégié à la maison uqamienne - j'aimerais simplement que tu rappelles ce qui t'attirait tout à coup dans cette nouvelle université et ce nouveau département qui devait, par définition, être original? Tu te souviens, on n'avait pas le droit de redoubler ce qui se faisait ailleurs d'où ce titre de département qu'il fallait trouver, département «d'esthétique». Tu travailles à ce moment-là avec Hubert Aquin, pourrais-tu évoquer rapidement cette époque?

M. v. Schendel - Je pourrais dire que d'une part j'aimais beaucoup l'enseignement, j'aimais beaucoup le contact avec les étudiants, j'aimais former des étudiants, j’aimais écouter les étudiants, ça m'était devenu indispensable. Mais, en même temps, dans cet exercice d'une passion - c'en était une, très fatigante aussi parce que c'était une passion - il y avait de constantes résistances opposées au plan du programme. À l'Université de Montréal par exemple, j'étais déjà très sensibilisé aux premiers travaux français en sémiotique, ça remonte à vingt ans, ce n'est pas nouveau l'intétêt que je porte à l'art et à la sémiotique mais à la sémiotique du texte telle que Barthes la pratiquait et telle que Tel quel essayait de la relayer malgré les effets de mode qui, déjà à ce moment-là, m'embêtaient beaucoup. J'avais également lu Blanchot et cette réflexion sur l'écriture par elle-même m'intéressait d'autant plus qu'elle recoupait ma propre expérience d'écrivain. Et je ne pouvais pas trouver dans les structures de programme existantes une place, un lieu vrai ment pour l'enseignement de la sémiotique ou l'enseignement des théories de la littérature, c'était encore plus large que la sémiotique. De ce point de vue-là, d'abord au Sainte-Marie, il y avait une tolérance plus grande et surtout à la fondation de l'UQAM il y avait à ce moment-là, la possibilité de créer de toutes pièces un programme qui puisse accueillir structurellement, organisationnellement plus exactement, ces tendances nouvelles de la critique et de la théorie. Et c'est ça qui me passionnait. Mais en même temps, et là très vite on s'en est rendu compte, ça ne pouvait se faire que dans le conflit, conflit à l'intérieur du département : de nombreux collègues refusaient, ceux-là mème qui aujourd'hui se disent sémioticiens, radicalement ces orientations que j'avais cependant soumises à la discussion. Il y avait une tendance dans ce grand "foutoir", qui était le département au tout début, à la sécurité et donc au repliement sur les départements existants, ce qui était la mort pour nous.

V. \& I.(1) - Une tendance modulaire aussi?

M. v. Schendel - Il y avait aussi une tendance modulaire très créativiste et je combattais les tendances créationnistes ou créativistes, créationnistes plutôt que créativistes.

V. \& I.(1) - On est arrivé à l'époque où tu trouves ta base la plus solide: du côté de l'enseignement. C'est à partir d'une pratique pédagogique qu'à qua- 
rante ans, tu reviens à une pratique politique et tu accuses davantage celle de l'écriture. Il y a là comme un lieu et comme un temps qu'on pourrait appeler de la maturité. Est-ce que tu pourrais, dans un rapport plus global, nous dire ce qui, pour toi, se dit là? Pédagogie, syndicalisme, écriture, tout ça me paraît lié mais j'aimerais que tu nous donnes ton point de vue.

M. v. Schendel - Je crois qu'il y a une toute première réponse et encore une fois elle tient à la conjoncture de ma vie professionnelle. Pour la première fois en 1968, j'ai la chance d'accéder à un emploi permanent, à un emploi stable, un emploi régulier - non pas sans heurts, il y en a eu, des heurts, et combien! - mais un emploi régulier et pour une longue période. Je n'avais jamais eu cette possibilité, même quand j'étais journaliste: le journalisme était en crise. J'avais été journaliste régulier au Nouveau journal mais le Nouveau journal n'avait duré que dix mois. J'avais-travaillé à La Presse où j'aurais pu demeurer s'il n'y avait pas eu toutes sortes d'avatars politiques, et finalement je ne pouvais plus continuer. Par la suite, $\mathrm{j}$ 'avais eu des emplois de fortune. J'avais travaillé, il est vrai, pendant deux ans et demi pour la Commission provinciale d'urbanisme puisque j'étais chargé de la maîtrise des recherches, de la fin des recherches et de la rédaction du rapport. Mais c'était un emploi limité. Une fois le rapport terminé, il était entendu que je partais. De toute façon, je n'aurais pas passé ma vie dans un bureau d'urbanisme même si ça m'a appris énormément. Toutes ces activités, bien sûr, m'avaient préparé et puis il y avait eu une continuité dans l'enseignement jusque-là, une certaine continuité mais dans des conditions d'instabilité. J'ai été chargé de cours pendant très longtemps et à une époque où être chargé de cours, c'était participer à un statut beaucoup plus précaire qu'aujourd'hui. Ça, je crois que c'est un premier élément de réponse, mais c'est important parce que, à partir de ce moment-là, tout ce qui a mobilisé quelqu'un comme moi sur plusieurs fronts que j'ai tous dû ouvrir, parfois de façon concomitante, parfois de façon successive, m'avait préparé bien sûr à déployer, à continuer de déployer mais de façon plus ordonnée ces diverses activités, une fois que l'on me donnait la possibilité d'accéder à un emploi stable. Donc, je continue. Et dans quelle direction? Il y a un rapport effectivement très étroit entre la pratique enseignante et la pratique d'écriture, rapport qui devient beaucoup plus étroit qu'il ne l'avait été précédemment. Il avait commencé d'être assez étroit à partir de la fin des années de journalisme, sauf que pendant cette période je n'ai pratiquement rien publié au plan de l'écriture poétique ou narrative. J'ai beaucoup écrit pendant cette période-là mais je n'ai pratiquement pas publié ce que j'avais écrit, ce n'est toujours pas publié d'ailleurs. Peut-être qu'un jour je me déciderai, il restait très peu de choses quand j'ai fermé mes cahiers, c'est assez volumineux, c'est un ouvrage assez considérable qui est partiellement autobiographique mais une autobiographie qui est en même temps très imaginaire. Et certainement que "Il dit» avait été sous l'inflence directe, je crois, d'une participation plus active à l'enseignement en ce sens que, par l'enseignement, je me tenais davantage au courant de ce qui s'écrivait, de ce qui se publiait un peu partout, en France notamment. J'étais frotté de façon systématique aux nouvelles orientations critiques et par conséquent les problèmes de constitution de la forme devenaient beaucoup plus pertinents pour moi et je les investissais, ces problèmes-là, dans l'écriture, 
dans "Il dit». Ce que j'en ai publié de "Il dit» (seule la première partie a été publiée dans Voix et images du pays) il n'y a pas eu d'échos à ça - ça m'a assez découragé d'ailleurs - alors que si je l'avais publié dix ans plus tard, on aurait dit oui, ça c'est l'écriture... c'est ce qui se fait mais à l'époque ça ne se faisait pas. Et personne apparemment n'a compris, il n'y a pas eu d'échos. C'est quelque chose de terrible, je m'écarte peut-être un peu de la question, je fais des digressions comme d'habitude... C'est quelque chose d'assez terrifiant pour un écrivain de publier et que ce qui est publié, et pourtant il y a non seulement beaucoup d'efforts mais il y a une invention, ne reçoit pas d'accueil, aucun accueil. Un silence.

V. \& I.(1) - Un silence, c'est très parlant...

M. v. Schendel - Un silence, c'est la pire des censures.

V. \& I.(2) - C'est une censure mais ça parle aussi?

M. v. Schendel - Ça parle, oui mais ça parle de la façon suivante: ça parle par le non-dit, un non-dit absolu: on n'a pas de place et ce travail n'a aucune espèce de fonction, au-delà même de l'absence totale d'effet de reconnaissance qui est nécessaire à la relance de l'écriture. C'est par ma digression, un deuxième élément de réponse. Troisième élément de réponse, le travail, celui que j'ai qualifié d'intellectuel organique, d'intellectuel en tant qu'organisateur c'est-à-dire d'intellectuel qui, pour continuer d'exercer son métier, en l'occurrence le métier d'enseignant pour lequel il est enfin salarié, se heurtéà des obstacles considérables. Il ne faut pas oublier qu'encore une fois, j'étais sur la brèche, comme beaucoup d'autres je crois, mais sur la brèche, et c'était pas par hasard que quelqu'un comme moi fût à nouveau sur la brèche, c'est-à-dire fût une fois de plus engagé, employé dans un secteur d'activité extrêmement contesté socialement, mal accueilli. C'était le cas au tout début de l'UQAM et pendant des années c'est resté comme ça, pendant au moins dix ans: l'UQAM, c'est le dernier-né dont on ne veut pas, si je peux dire, parce que c'était un dernier-né qui n'avait pas de parents. Le ministère de l'Éducation, oui bien sûr et quelques sages de l'Université Laval qui avaient déposé un rapport dans les années 60 visant une restructuration du système universitaire dont le lieu devait être d'abord l'Université du Québec, organisation à structure modulaire, etc. Donc, il fallait se battre, une fois de plus il fallait se battre. Mais il fallait se battre de façon peut-être plus permanente, non plus simplement comme un franc-tireur mais de façon plus systématique et plus stable puisque tout de même, même si on n'en voulait pas de ce rejeton de la nouvelle université post-soixante-huit, en même temps cependant on ne pouvait pas s'en passer. Il fallait qu'elle fût là, ne serait-ce que pour attirer, comme sur un abcès de fixation, toutes les formes du mécontentement. Nous devenions donc le baudet.

V. \& I.(1) - D'où l'action syndicale?

M. v. Schendel - D'où l'action syndicale.

V. \& I. (1) - Est-ce que c'était pour toi une façon de continuer l'enseignement? ou de le multiplier ou de l'assurer? 
M. v. Schendel - C'était une façon de continuer l'enseignement sur le plan de l'aménagement des conditions visant à assurer une plus grande qualité et une plus grande efficacité de cet enseignement. Et c'était aussi une façon de continuer, au plan de l'organisation, les efforts de réflexion auxquels je m'étais soumis pendant des années et grâce auxquels j'avais dirigé la revue Socialisme notamment et publié des essais de réflexion politique. C'était donc un double prolongement; mais en même temps il faut bien dire que je n'avais guère le choix. Et j'avais d'autant moins le choix qu'on savait bien, mes camarades le savaient bien aussi, que dans la mesure où on devait former un syndicat, j'étais préparé pour ça, j'avais une expérience syndicale. Non seulement ça, mais j'avais le goût de cette organisation qui me paraissait absolument essentielle, c'était la seule chose qui demeurait. Après tous les désastres des années soixante, c'était la seule chose d'un peu stable qui demeurait, disons globalement, à gauche. Au plan d'une - un mot me vient, à la mode, mais j'ai horreur de cette expression, elle est celle d'une vacuité d'un autre "projet de société», ce qui ne veut strictement rien dire, d'une révision politique du système dans le sens d'un travail en profondeur, sur la voie plutôt de la constitution d'une alliance entre classes populaires et, dans ce travail d'alliance, il me semblait et il me semble toujours que les intellectuels avaient beaucoup à dire et qu'enfin ce travail d'intellectuel pourrait avoir une base sociale et un effet de reconnaissance aussi, beaucoup plus durable.

V. \& I. (1) - Mais tu écris tout de même pendant cette époque, disons des années soixante-dix?

M. v. Schendel - Oui.

V. \& I.(1) - Et après avoir publié dans Voix et images, en 1971, «Il dit», tu continues d'écrire et tu vas publier plus tard «Le dit des mots démis». Est-ce qu'il faut attacher une grande importance aux derniers éléments de ton titre «des mots démis »?

M. v. Schendel - Oui, je crois, c'est une très bonne question.

V. \& I.(1) - Qu'est-ce que ça veut dire? Il y a "démettre», «démission»?

M. v. Schendel - Non, c'est le mot "démis», comme un os est démis.

V. \& I.(1) - Sorti de son articulation?

M. v. Schendel - Oui, voilà. Exactement. C'est un travail que je faisais depuis longtemps déjà et c'était une vie.

V. \& I. (2) - Est-ce que ce n'est pas aussi un travail que je retrouve dans chaque recueil sur les syntagmes figés. Vous nous donniez justement l'exemple du Mot à gouttes, on retrouve dans Veiller ne plus veiller, je donne des exemples, il y en a beaucoup, $\overline{\mathbf{A}}$ pas de grèves... Il y en a d'autres dans Autres. Autrement, il y a comme un travail sur des expressions courantes, des expressions populaires que vous retravaillez et que le poète retravaille, et qui vont à la source du langage populaire. Le travail dans la forme, est-ce que ça ne se retrouve pas au niveau d'une problématique très large? 
M. v. Schendel - Oui, justement. Je faisais ce travail depuis plusieurs années mais dans le silence. Je le faisais et là vraiment je crois qu'il y a une articulation: au plan théorique, une relation avec la réflexion politique, au plan théorique aussi une relation avec le plan de l'expression. Le plan de l'expression - et je vous rappelle que j'avais fait des études de droit, et ce qui m'avait durablement intéressé dans ces études de droit, c'était le fonctionnement du discours, le fonctionnement de l'adage juridique donc le fonctionnement d'une cellule discursive qui, diraient les philosophes du langage, Goodman en particulier, participent des formes nomologiques, des formes donc de l'expression de la loi qui est une expression impersonnelle, dite neutre alors qu'elle ne l'est pas; elle est impersonnelle, et son énonciateur est un "on" - ces études m'ont amené, à partir des années soixante-dix de façon très systématique et ça a débouché, et là il y a eu un virage dans mon travail théorique, m'ont amené à travailler les problèmes de l'institution. L'institution pour moi, c'est ça. Ce n'est pas de l'ordre du fonctionnement politique bien que ça traverse le fonctionnement politique d'appareils. L'institution, les phénomènes de l'institution sont de l'ordre du discours, du geste mais par lesquels sont énoncés impersonnellement des axiomes à valeur généralisante, applicables universellement et quelles que soient les conjonctures et c'est évidemment le cas du proverbe ou l'adage. Et si on travaille le proverbe ou l'adage, on ne peut travailler ces formes nomologiques qu'en étant en même temps très conscient du caractère poétique de ces fragments formulaires. Je dis bien fragments et là on rejoint le mot «démis». Le fragment, parce que la forme nomologique n'apparaît jamais qu'à l'état d'un reste, quelque chose a été oublié et quelque chose demeure qui renvoie à cet oubli. C'est ce renvoi à cet oubli, lui qui a été historiquement réalisé, qui assure en même temps la pérennité, la stabilité, pour maintenant, des conditions d'emploi de ce fragment. Travailler donc en ce sens, c'est faire du travail poétique. Et c'est le même travail que celui de la réflexion de poéticien. De poéticien, oui. Ici, une évocation. J'avais au début de mon enseignement, dans des conditions de stabilité, travaillé beaucoup le discours poétique. Dans mon enseignement, j'avais, en particulier au Collège Sainte-Marie en 68-69, donné deux cours, l'un sur la poésie surréaliste et l'autre sur la poésie québécoise depuis le Refus global. Le rappel studieux des surréalistes, précisément, m'avait permis de voir techniquement, si je puis dire, - je ne suis pas du tout un surréaliste, mais j’ai été quand même très fortement, au plan technique, mis en rapport avec le travail des surréalistes - leur travail sur la constitution et le déplacement de la métaphore (parce que c'est essentiellement une poésie de métaphores) un travail qui consistait à débusquer les formes nomologiques et à les amener à dérive d'une façon très systématique, bien que hasardeuse. Je trouvais qu'il y avait une sorte de perte ou de légèreté dans cette sortie de hasard du côté des surréalistes, et ça c'était très intéressant, le travail en particulier sur les proverbes. Vous parliez tout à l'heure d'Éluard, on peut également parler de Breton, aussi surtout parler de Benjamin Péret. Benjamin Péret, c'est un travail systématique sur les formes proverbiales. D'une part, donc, ce travail d'enseignant de la poétique. D'autre part, une fréquentation professionnelle en tant que critique. J'ai été critique assez longtemps et critique de toute la production poétique québécoise dans les 
années cinquante et j'ai continué pendant les années soixante, j'étais donc bien au fait de ce qui se tramait depuis longtemps; et je m'étais aperçu qu'en fait, c'était par l'écriture poétique qu'on arrivait à une forme et un développement et à des conditions de stabilité, à ce qu'on pouvait enfin appeler une littérature, une littérature québécoise. C'était par le discours poétique essentiellement, parce que c'était là qu'il y avait une invention. Ce n'était pas dans le roman, même s'il y avait de bons romans, ces romans en fait ne découvraient pas les formes particulières du monde québécois, ne découvraient pas sa place parce qu'il n'y avait pas de travail précisément sur la forme. Donc, je m'étais rendu compte que travailler sur la forme, l'inventer, c'est-à-dire la fragmenter par rapport à l'existant, c'était en même temps le seul moyen de situer la fonction sociale de la littérature et de faire en sorte que la littérature annonce, au plan idéologique, sa propre référence. En d'autres termes, cette référence ne tient pas aux «thèmes» exploités, et en ce sens tout ceux qui ont parlé de la poésie du "pays " n'ont rien compris, surtout quand ils me l'appliquaient, parce que la thématique n'avait aucune espèce d'importance sauf, bien sûr, tout ce qui, de l'exil, recoupe le fragment, recoupe la perte, recoupe l'oubli mais aussi la constitution d'une autre mémoire. Une autre mémoire, il y avait à la découvrir, elle était déjà là, mais elle avait été abolie. Sinon, une thématique n'est rien, n'est même pas anonyme, ce n'est pas une forme et ce n'est donc pas de cette façon-là qu'on peut mesurer ou analyser les fonctions idéologiques de la littérature, c'est-à-dire sa place par le biais des fonctions idéologiques, sa place dans l'univers social et politique, sa place dans le monde des antagonismes de classes.

V. \& I.(1) - D'où cette nécessité de démettre les mots?

M. v. Schendel - Exactement.

\section{De l'oeil et de l'écoute}

V. \& I.(1) - Quand tu rassembles tes écrits dans de l'Oeil et de l'écoute, tu dis précisément il y a des choses de l'aeil, il y a des choses de l'écoute...

M. v. Schendel - Excuse-moi de t'interrompre mais je me suis aperçu beaucoup plus tard que c'était une reprise d'un vers de Valéry. Ça, je ne m'en étais absolument pas rendu compte, ce sont de ces hasards qui arrivent, des formes plagiaires involontaires. Mais dans l'Oeil et l'écoute, il y a l'œil mais il y a la fonction plus qu'auditive, ce n'est pas l'œil et l'oreille, ce n'est pas deux organes différents mis ensemble. C'est donc un décalage.

V. \& I. (1) - Oui, mais je veux en arriver à ceci: puisque tu accuses la dimension de la fonction sociale de ton écriture, je la vois se marquer davantage quand tu passes des choses de l'écriture de l'œil à celle de l'écoute parce qu'alors on passe vraiment du descriptif au transcriptif. Quand tu dis démettre les mots c'est-à-dire prendre les mots de ceux qui t'entourent dans la vie et les transcrire en les déplaçant, cela s'applique parfaitement, et peut-être davantage, à cette deuxième dimension, celle de l'écoute. Quand tu dis dans tes derniers textes qui consistent à donner ton art poétique, quand tu dis de l'œil 
et puis ensuite de l'écoute, on te suit très bien dans le discours que tu viens d'établir, en tout cas dans le point de vue théorique que tu établis pour ton écriture parce que tu transformes précisément l'écoute en écriture comme si tu devenais plus attentif qu'auparavant à ce qui est dit. Parce que ton écriture devient plus d'occasion, de circonstance mais alors d'exploitation maximale de ce circonstanciel qui te conduit au fragmentaire, au dénombrement, à la musique aussi? Alors, démettre les mots voilà ce que ça veut dire, c'est revenir à une fonction encore plus accusée, socialement parlant, à une fonction référentielle plus nette et je la vois encore s'accuser davantage dans Veiller ne plus veiller où, là, tu nous donnes les clés des énigmes que tu as pu monter...

M. v. Schendel - Je ne donne pas les clés.

V. \& I. (1) - Tu en donnes beaucoup pour une personne qui n'aurait pas vécu l'événement syndical...

V. \& I.(2) - Il y a beaucoup d'humour dans Veiller ne plus veiller. Au fur et à mesure que vous dites des choses qui peuvent être idéologiques, vous faites intervenir l'humour.

M. v. Schendel - Oui, c'est un travail incessant de déconstruction. Ce n'est pas simplement... il ne faut pas tomber dans le piège, on y tombe dans le piège, les pièges sont là pour qu'on y tombe mais il faut bien savoir que ce sont des pièges et il faut donc les pointer. À ce moment-là, il faut multiplier les registres de l'écriture, d'où la bonne et la mauvaise page.

V. \& I. (1) - D'où le paratextuel. Le paratextuel, dans ton écriture, est d'abord signalétique. Pour quelqu'un qui voit ça de l'extérieur, tu signales de temps en temps, dans un premier temps disons, pour le premier versant de ton texte, toute l'importance que tu accordes à l'amitié. On sent que ton environnement est davantage celui de l'amitié que du social en général, dans le paratexte tu signales, tu donnes des indices assez minces...

M. v. Schendel - L'amitié est l'ancrage, c'est ma situation à moi ou à celui qui écrit. C'est mon ancrage mais mon ancrage dans quoi? Précisément dans un monde, dans une forme sociale qu'il s'agit d'organiser. L'amitié est plus que signalétique, elle est aussi un ancrage et par conséquent elle participe de l'organique.

V. \& I. (1) - Bien sûr, elle est même thématisée. Je ne veux pas réduire l'amitié au signal que tu en donnes mais je veux dire que le paratexte est modeste au départ mais plus ton œuvre se développe, plus ce paratexte se développe et plus on sent la théorie ou ton art poétique investir l'expression au point où tu arrives dans Autres. Autrement à donner ces entrecroisures qui sont un véritable commentaire et une mise en situation théorique de l'ensemble. Alors là, on sent davantage la construction comme si tu disais à ton lecteur "puisque tu ne m'as pas lu suffisamment, puisque tu n'as pas mis à jour, jusqu'à maintenant, suffisamment, les constructions que je t'ai propo- 
sées, voilà, je vais t'en donner davantage ". Voici que dans Autres. Autrement la structure devient apparente, le discours poétique devient beaucoup plus théorique. Est-ce que c'est juste de te lire ainsi?

M. v. Schendel - Je crois que c'est juste. Oui, c'est tout à fait juste et à partir de ce moment-là le travail d'écriture est un travail systématique sans construire un système, au contraire.

V. \& I.(1) - Ou alors le «système» est désorienté, parce que tu n'installes pas tes entrecroisures de façon systématique, tu ne les places pas vraiment toujours aux transitions d'un bloc à l'autre, tu les déplaces et on sent là qu'il y a une musique comme tu dis.

M. v. Schendel - Oui. Il y a une petite nuance que j'aimerais cependant introduire. De la façon dont tu l'as dit et tu l'as dit très clairement, beaucoup plus clairement que je ne saurais le dire en si peu de temps, tu as quand même laissé entendre que, en fait, $j$ 'avais une position pédagogique, en quelque sorte le maître, l'écrivain qui fait la maîtrise aux lecteurs. Je ne suis pas d'accord, là c'est un autre piège. Une partie de ce piège est inévitable, il y a bien sûr une position didactique et je rappelle que les premiers poèmes publiés comportaient des poèmes didactiques. Il y a donc certainement un apprentissage didactique de l'écriture, apprentissage didactique que je profilerais de la façon suivante: en rappelant peut-être, je ne fais pas le même travail que Brecht, mais en rappelant tout de même le travail de Brecht, c'est-à-dire une didactique bien particulière qui consiste dans la distanciation et dans la mise en distance. En ce sens, je ne fais pas la leçon au lecteur, je n'ai aucun droit à lui faire la leçon. Mais si j'engage un dialogue, ou un polylogue plutôt, avec le lecteur, c'est vraiment d'un polylogue qu'il s'agit, je lui demande de participer à ce travail et à cette rigueur mais, en retour, je dois énoncer les conditions de cette rigueur. C'est une simple honnêteté intellectuelle, ce n'est pas simplement une condition morale ou mythique, c'est aussi la seule façon de faire le travail de l'écriture.

V. \& I.(1) - Et de le rendre apparent.

M. v. Schendel - Le rendre apparent et ainsi lui permettre de se développer pour qu'il acquière ses conditions propres, son autonomie propre dans l'efficacité.

V. \& I.(2) - Ce que vous disiez sur le paratexte, ça devient texte. C'est un statut ambigu, ambivalent parce que si on le prend simplement comme quelque chose de signalétique, à ce moment-là on se trompe. Il est ça et puis en même temps il ne l'est pas. À partir du moment où vous le mettez... Il est signalétique, il est indiciel mais il participe de la forme et à ce moment-là il n'est plus seulement indiciel.

V. \& I.(1) - C'est tellement vrai que, quand on arrive à Autres. Autrement, on est très loin de l'indiciel de Veiller ne plus veiller. Dans Autres. Autrement, ce-que j'appelle- «les textes-plus théoriques-» - les fameuses entrecroisures 
qui sont données en italique - ce n'est pas une dissertation, jamais, c'est un discours poétique qui transcende le théorique au sens strict, qui le transforme. Tu joues, tu introduis les images à partir de ta proposition, disons théorique, initiale, sur l'inaugural, le monumental; très rapidement on sent que tu transformes les idées que tu veux proposer. Ce qui est amusant, c'est que tu le constitues par là : le paratexte n'existe plus, c'est du texte parce que tu constitues là un livre dans le livre, et tu nous invites toi-même à jouer le jeu, c'est-à-dire que tu justifies par là la datation des poèmes. Quand on regarde les dates de ces textes en italique, ces fameuses entrecroisures, on se rend compte que tout ça est écrit à l'automne 1979, dans la procédure même d'organisation, de constitution du livre, du texte entier. Donc, il n'y a plus paratexte, je suis tout à fait d'accord, mais ça commence comme un paratexte et puis ça se fait texte. Ça travaille toujours dans la contradiction, la recherche d'une synthèse est toujours provisoire.

V. \& I.(2) - Est-ce que ce n'est pas aussi le fait d'un poète qui... Il y a tous les clichés, qui ont cours encore, qui veulent que les poètes soient des gens qui ne théorisent pas.

M. v. Schendel - Les plus grands poètes sont les plus grands théoriciens. Nécessairement.

V. \& I. (2) - Comme Hopkins par exemple et sa théorie du «Sprung Rythm "?

M. v. Schendel - Voilà, c'est ça. C'est une expérience de théoricien mais de théoricien d'une théorie qui est une pratique. C'est dans ce sens que j'avais écrit et publié d'ailleurs dans «le Dit des mots démis", à la fin de De l'Oeil et de l'écoute, ce texte qu'on avait eu la gentillesse de publier dans Voix et images, "Cette écriture» où je montre comment, de façon immédiate et techniquement, se fait le travail d'écriture, comment je constitue le texte poétique.

\section{Écrire: la métécité}

V. \& I. (1) - Qu'est-ce qu'écrire aujourd'hui au Québec pour toi? Quelles sont les conditions de l'écriture aujourd'hui et où t'en vas-tu de ce côté-là?

M. v. Schendel - Il y a beaucoup de questions. Je vais commencer ainsi. Je dirais que, phénoménalement, je suis un métèque. Structurellement, écrire pour moi, c'est pratiquer la métécité.

V. \& I.(1) - L'exil.

M. v. Schendel - C'est plus que l'exil, c'est l'étrangeté, c'est pratiquer l'étrange parce que l'étrange est précisément ce qui transforme. Je réponds par des aphorismes mais...

V. \& I.(1) - C'est très clair. 
M.v. Schendel - L'un des aspects de la question que vous avez posée tout à l'heure, le fait que par exemple les productions telles que les miennes on les passe sous silence, cè n'est pas nouveau et ça tient très certainement à ce que je viens de dire de la métécité. Non pas parce que simplement, moi comme individu, je suis un métèque, je revendique ce titre mais parce qu'écrire et inventer, c'est pratiquer la métécité, c'est pratiquer la transformation, c'est pratiquer donc l'extérieur-intérieur. Il n'y a plus d'extérieur et il n'y a plus d'intérieur mais c'est toujours faire le passage, non pas se situer dans l'audelà, il n'y a pas d'au-delà, mais c'est faire le passage qui élargit la forme, qui est cette voie de passage transformateur avec les matériaux existants et qui met en place, provisoirement, un inédit, quelque chose qui n'existe pas encore, quelque chose qui n'existe pas et dont cependant on a besoin pour penser et pour agir. C'est ça écrire. De ce point de vue-là, si c'est pratiquer l'étrange ainsi décrit, ainsi présumé, il n'y a rien d'étonnant à ce que cette invention scripturale soit méconnue. D'autant moins étonnant, elle pourrait ne pas être méconnue ailleurs, mais d'autant moins étonnant que nous sommes au Québec, que les fonctionnements instituants, de l'ordre de l'institution, au Québec sont rudimentaires, sont très pauvres et je dirais encore très nouveaux, spécialement en ce qui concerne l'institution littéraire.

\section{V. \& I.(1) - C'est-à-dire?}

M. v. Schendel - C'est-à-dire l'écriture. Alors que, au contraire, le fonctionnement des appareils, lui, est foisonnant et même anarchique. Il n'y a qu'à voir la constitution quasi féodale de notre scène politique. Il y a un foisonnement considérable d'appareils qui s'enchevêtrent, qui, juridiquement, se distinguent mais se chevauchent. Bon, c'est le fait de tous les appareils, un appareil ne peut être que politique, mais cela est encore surdéterminé par le caractère féodal des champs de compétence: gouvernement municipal, gouvernement provincial, gouvernement fédéral, police officielle, police privée, police parallèle, etc. Alors que les fonctions sociales de tous ces appareils sont identiques, il y a une espèce de sur-accumulation d'appareils. Dans un tel décalage et une telle démesure entre la règle instituante ou les règles, les codes au sens juridique du terme ou l'ordre canonique de la règle, d'une part, qui est relativement pauvre - pauvre ou alors on trouve un autre type d'institution, c'est l'institution canonique et ce n'est pas l'institution littéraire - et les foisonnements d'appareils, il n'y a pas de doute que cette situation, ce déséquilibre, doit normalement se traduire par un retour, une régression, précisément à l'institution canonique et par conséquent une tentative de syncrétisation de l'institution canonique et des appareils existants. Par conséquent, à ce moment - là, il y a des tentatives de prises de pouvoir, d'autant mieux assurées que, précisément, très peu sont à même de prendre le pouvoir; il suffit qu'ils s'organisent suffisamment et c'est ce que l'écriture dite de la modernité, enfin qui se proclame, s'auto-réclame de façon exclusive comme prafique de la modernité, a entrepris de faire depuis déjà plus de dix ans. Je trouve ça dommage et très dangereux pour la littérature québécoise parce qu'elle risque d'étouffer. Sa diversité, sa pluralité risquent fort d'en pâtir. Je suis d'aussi près que je peux et depuis quelques années je lis toutes 
les productions poétiques qui paraissent chaque année, il y a un immense travail que je trouve très attachant sur la matérialité et parfois il y a une percée du côté de l'invention. Je dirais que le travail de Nicole Brossard participe de ça. Je reprocherais cependant au travail de Nicole Brossard de limiter l'inventivité, l'invention scripturale, au seul monde dit intérieur, hors référence, hors histoire, hors historicité organique de la formation sociale. $\mathrm{Ca}$, c'est une sérieuse entrave, je crois, au prolongement de ce travail incontestable d'invention scripturale qui est le sien. Je trouve encore plus, malgré la nomination de la référence sociale, chez certains jeunes écrivains comme Corriveau que l'horizon est encore plus étroit. Ce qui me frappe, c'est que, dans l'immense majorité de ces productions très nombreuses et ils publient énormément, il y a un moule qui est toujours le même et qui est toujours répété. Il n'y a plus d'écriture singulière, de moins en moins. Il y a des formats d'écriture. Et toutes sortes de textes, nominalement différents, répètent le même format.

V. \& I.(1) - Tu ne penses pas que ça a beaucoup changé depuis un ou deux ans? Est-ce que Nicole Brossard elle-même et les autres qui l'entourent n'ont pas changé? Si je me fie au dernier colloque de la Barre du jour qui est paru en 84 dans Vouloir la modernité, je me rends compte qu'il n'y a plus personne qui revendique le formalisme et que la plupart des jeunes qui publient depuis quelques années vont précisément du côté de la singularité et brisent le carcan formaliste. Nicole Brossard elle-même s'est adonnée à une pratique autobiographisante de l'écriture. Je pense à André Beaudet, je pense à François Charron, je pense à plusieurs exemples de singularisation, peut-être d'une subjectivité, en tout cas d'un rejet.

M. v. Schendel - Oui, mais ils sont marginalisés ces gens-là. Moi aussi je pensais à Beaudet. Je suis assez sensible au travail d'André Beaudet. Là, je crois qu'il y a vraiment une invention mais Beaudet est marginalisé, il est exclu d'ailleurs.

\section{Publier}

V. \& I.(1) - Que fais-tu maintenant, que devons-nous attendre côté publications?

M. v. Schendel - Je peux parler du programme immédiat. À plus long terme, je ne sais pas. Je dois remettre sous peu - je devais le remettre cette année, je n'ai pas pu parce que j'ai été malade et j'ai dû suspendre toute activité pendant deux mois, je n'ai même pas pu écrire ou très peu -le manuscrit d'un livre qui s'appelle Extrême/livre des voyages qui est lui-même composé de trois livres: Suite pour un silence, que vous allez publier. C'est l'ouverture du livre. Le deuxième, Cammin'. Suite pour un silence est composé de trois parties. Cammin' est composé de quatre parties sous l'inspiration inaugurale du premier vers du premier chant de l'Enfer de Dante: «Nel mezzo del cammin' di nostra vita ${ }^{4}$. Une partie de ce texte a été publiée, mais ce sont des extraits seulement, dans Estuaire. La première partie c'est 
"Mezzo", puisque c'est déjà le milieu mais c'est le premier, on est déjà dans l'objet. C'est la maturité. "Intermezzo", "Andante», qui est alors le temps du voyage. C'est pourquoi Cammin' a sa place dans l'Extrême/livre des voyages. Cammin', c'est chemin et c'est cheminement. Et la dernière partie Chant de la Bombarde, composée de trois parties: "Muser", "Pâlir de voix", "Cheminer». Cette quatrième partie de Cammin', elle, fera l'objet d'une publication distincte dans un livre d'hommage à Jean Levaillant qui sera publié aux Éditions de l'Université de Paris VIII. Enfin, le dernier livre de l'Extrême/livre des voyages s'appelle Voyage au-dessus des rails.... Pourquoi ce titre? Je dirais tout naïvement et tout bêtement parce que, comme on dit en anglais, je suis un "commuter», je fais la navette pour des raisons existentielles, ma compagne vivant à Toronto, entre Montréal et Toronto, allerretour par le train, plus rarement par l'avion. Aussi parce que j'ai accumulé, depuis les dix dernières années, une expérience de voyageur qui est celle de la prise à distance, essentiellement c'est ça, du désenchantement au sens littéral : si l'on pratique le chant, il faut dé-chanter et désen-chanter, faire entendre ce qui est dit à travers le chant. L'ensemble du livre se termine sur un texte que je peux vous lire, ça serait peut-être la conclusion. Il est assez court: "Quand l'imagination de Piscator invente mon père adversaire et camarade". Piscator, vous savez qui c'était?

V. \& I.(2) - Non, je ne sais pas.

M. v. Schendel - C'est un immense bonhomme, un très grand créateur, on peut le dire, créateur de formes du théâtre allemand de l'entre-deux-guerres. Il est mort dans les années 60,65 ou 66. C'était un homme de gauche qui a expérimenté sur la scène de ses nombreux théâtres la polyvalence de l'expression dramaturgique classique, des moyens visuels et scéniques de cette expression, du cinéma, de la peinture, de la bande dessinée, tout cela dès le début des années 20 , au tout début des années 20 . C'est un homme dont la vie et aussi les formes inventées ont été constamment persécutées, même avant le nazisme. Il a dû subir l'Allemagne au moment de l'arrivée des Nazis. C'est un de ces immenses, tellement chaleureux et émouvants Allemands anti-nazis auxquels nous devons tant.

V. \& I.(1) - Et quel autre livre avais-tu annoncé tout à l'heure?

M. v. Schendel - Il y a Sentiers critiques dont un fragment, un fragment de vingt pages, c'est mon journal politique. Il paraîtra dans les cahiers annuels Sédiments dont Georges Leroux et moi dirigeons la publication chez H.M.H. Doivent paraître également cette année divers poèmes dans une revue française Sud et également dans une petite revue belge. D'autres textes ont été traduits et publiés au Mexique. Il est question également, mais ça c'est un vague projet, de publication en traduction au Brésil.

V. \& I.(2) - Est-ce que vous êtes traduit en anglais?

M. v. Schendel - Non, je ne sais pas... L'éditeur fait mal son travail ou ne m'informe pas, ni des comptes rendus ni des traductions. J'ai découvert ainsi, 
par hasard, lors d'une exposition rétrospective des Éditions de l'Hexagone, qu'un de mes poèmes avait été traduit en italien. Je n'avais jamais été informé.

V. \& I.(1) - Qu'est-ce que tu prépares en dehors des publications?

M. v. Schendel - Il y a également Histoire de Jousse qui est terminé, que j'avais terminé en 83, qui paraîtra mais je ne sais pas où, je ne l'ai envoyé encore à aucun éditeur. Il y a aussi, ça devrait paraître avant la fin de cette année je suppose, ça dépend de moi, mon gros bouquin Formes et institutions, le titre général étant le Trébuchet de Dante.

V. \& I.(1) - C'est ta thèse de doctorat?

M. v. Schendel - C'est ma thèse de doctorat.

V. \& I.(2) - Thèse de troisième cycle? d'état?

M. v. Schendel - D'état.

V. \& I.(2) - Doctorat d'état que vous faites à Paris VIII, c'est cela?

M. v. Schendel - Oui.

V. \& I. (1) - Ça fait une année très chargée quand on y pense bien, en publications.

M. v. Schendel - Oui et il y a à travers tout ça les directions de thèses et de mémoires.

V. \& I.(1) - Et l'enseignement aussi.

M. v. Schendel - Et l'enseignement et je serai à Toronto dans le cadre des échanges avec le département français de Toronto, à l'automne, pour donner un cours de Graduate Studies. C'est très chargé.

V. \& I.(1) - Tu as bien besoin de vacances alors?

M. v. Schendel - Oui, j'ai besoin de vacances.

Montréal, 11-19 juin 1985
1. Jacques Allard
2. Michel van Schendel
3. Chantal de Grandpré
4. En français: "Au milieu du chemin de notre vie". 